\title{
A common gene expression signature in Huntington's disease patient brain regions
}

\author{
Andreas Neueder ${ }^{*}$ and Gillian P Bates ${ }^{*}$
}

\begin{abstract}
Background: Gene expression data provide invaluable insights into disease mechanisms. In Huntington's disease $(H D)$, a neurodegenerative disease caused by a tri-nucleotide repeat expansion in the huntingtin gene, extensive transcriptional dysregulation has been reported. Conventional dysregulation analysis has shown that e.g. in the caudate nucleus of the post mortem HD brain the gene expression level of about a third of all genes was altered. Owing to this large number of dysregulated genes, the underlying relevance of expression changes is often lost in huge gene lists that are difficult to comprehend.

Methods: To alleviate this problem, we employed weighted correlation network analysis to archival gene expression datasets of HD post mortem brain regions.

Results: We were able to uncover previously unidentified transcription dysregulation in the HD cerebellum that contained a gene expression signature in common with the caudate nucleus and the BA4 region of the frontal cortex. Furthermore, we found that yet unassociated pathways, e.g. global mRNA processing, were dysregulated in HD. We provide evidence to show that, contrary to previous findings, mutant huntingtin is sufficient to induce a subset of stress response genes in the cerebellum and frontal cortex BA4 region. The comparison of HD with other neurodegenerative disorders showed that the immune system, in particular the complement system, is generally activated. We also demonstrate that HD mouse models mimic some aspects of the disease very well, while others, e.g. the activation of the immune system are inadequately reflected.
\end{abstract}

Conclusion: Our analysis provides novel insights into the molecular pathogenesis in HD and identifies genes and pathways as potential therapeutic targets.

Keywords: Neurodegenerative diseases, Huntington's disease, Transcriptional dysregulation, Network analysis, Therapeutic targets

\section{Background}

Huntington's disease (HD) belongs to the group of polyglutamine (polyQ) repeat expansion diseases, which together comprise the most common form of inherited neurodegenerative disorders [1]. It can also be categorized as a proteinopathy, a disorder in which abnormally folded proteins cause disease by loss- and/or gain-of-function mechanisms. Many other neurodegenerative diseases also belong to this category. For example aggregating proteins include the amyloid- $\beta$ peptide $(\mathrm{A} \beta)$ and tau (MAPT) in Alzheimer's disease (AD) [2] and $\alpha$-synuclein (SNCA) in Parkinson's disease (PD) [3]. The major aggregating

\footnotetext{
* Correspondence: andreas.neueder@kcl.ac.uk; gillian.bates@kcl.ac.uk

Department of Medical and Molecular Genetics, King's College London, London SE1 9RT, UK
}

proteins in amyotrophic lateral sclerosis (ALS) are superoxide dismutase 1 (SOD1) [4], TDP-43 (TARDBP) [5] and FUS [6]. However, other diseases that are not associated with misfolded proteins can also result in major neurodegeneration. Amongst these are brain tumors, e.g. gangliogliomas (GG) [7], which arises from brain ganglion cells, and inflammatory diseases such as multiple sclerosis (MS) which can result in a massive loss of neurons [8]. Furthermore, there is evidence that even very heterogeneous mental illnesses, such as schizophrenia (SCHIZ) are at least partly associated with neurodegeneration [9].

Whilst many of the above diseases are characterized by mutations in protein coding regions, mutations can also exert deleterious effects through RNA molecules. A hexanucleotide repeat expansion in the uncharacterized gene 
C9orf72 is the most common cause of familial and sporadic ALS, as well as frontotemporal lobar degeneration (FTLD) $[10,11]$. The repeat expansion is located in intron 1 of $C 9$ orf72, thereby making it an RNAopathy, i.e. a toxic gain-of-function of an RNA leading to disrupted protein and/or RNA homoeostasis [12]. RNA gain-of-functions also occur in other repeat expansion diseases such as myotonic dystrophy type 1 (DM1) and type 2 (DM2) [13]. In DM1 the DMPK gene harbors a large repeat expansion in the 3' untranslated region [14-16]. In DM2 the repeat expansion is located in intron 1 of the ZNF9 gene [17]. The splicing factor MBNL1 is recruited to the repeat expansion in both cases [18], which in turn leads to a disruption of general mRNA processing resulting in cytotoxicity. Intriguingly it was recently shown that in HD a short transcript of the HTT gene is produced by aberrant splicing, probably influenced by abnormal binding of the splicing factor SRSF6 to the CAG repeat expansion [19]. In addition to the alternative splicing of HTT itself, other aberrantly spliced transcripts can be found in HD mouse model tissue (Gipson TA and Housman DE, unpublished data).

Transcriptional dysregulation, or a global change in gene expression is a hallmark of many neurodegenerative diseases, including HD, AD, PD and ALS [20]. For HD there is some evidence in patients [21-23] and mouse models $[24,25]$ that these changes occur in the prodromal stage, which could make them useful to define disease progression on a molecular level, or even as potential biomarkers for therapeutics. Intriguingly, mutant huntingtin (HTT) itself was found to exert abnormal DNA binding activities [26]. The authors proposed that mutant HTT binding could alter DNA structure or sterically block access by other transcription factors and therefore be the initial cause of HD transcriptional dysregulation. The biggest study to date of human samples analyzed 44 HD patient and 36 control brains [27]. They found extensive changes in the caudate nucleus $(\mathrm{CN})$ and BA4 region (motor functions) of the frontal cortex (FC-BA4). Almost no changes were found for the BA9 region (association, cognitive functions) of the frontal cortex (FC-BA9), or the cerebellum (CB). In a follow up study, the same group showed that the changes seen in HD patients were largely comparable to changes seen in HD mouse models [28].

However, standard evaluations of large, multidimensional gene expression datasets need to apply very strict statistical thresholds to correct for family wise errors stemming from the very high number of multiple comparisons. In doing so, small and/or maybe more heterogeneous expression changes may not be detected. Yet these small changes could contribute to an overall functional deficit, if they for example are all part of a certain molecular pathway. Alternatively, they may represent large changes in a subpopulation of cells. One solution to this problem is to analyze the data with correlation networks, which provide a more systemic view, instead of a per gene assertion. Weighted gene correlation network analysis (WGCNA) is a package of $\mathrm{R}$ functions, which allows one to construct such networks [29]. In these networks, groups of genes, which highly correlate in their expression, are clustered into modules. Next, these modules can be correlated to external traits, for example disease stage, age, sex, etc. Because only a small number, usually in the range of 10 to 30 modules per network, are identified, multiple comparisons are greatly alleviated. Another huge advantage is that one can detect "hub genes", i.e. genes that are the highest connected genes in a particular module and are therefore most likely the biological key drivers. These hub genes also present bona fide therapeutic targets and/or biomarkers. WGCNA was successfully used to analyze many large datasets, noteworthy in the identification and cross-species comparison of brain region networks [30,31] and in the analysis of gene expression changes in ALS [32] and AD [33,34].

Here, we used WGCNA to study the transcriptional dysregulation in HD. To this end we constructed and compared networks for 4 different regions from patient brains and analyzed their preservation in gene expression datasets of other diseases, as well as in mouse models of HD. We constructed consensus networks of HD and other diseases to highlight common changes. These approaches allowed us to identify a common signature of transcriptional dysregulation in all three brain regions and to pinpoint potential future therapeutic targets.

\section{Results}

Weighted correlation network construction using WGCNA in the HD dataset

For a more detailed explanation of the WGCNA package, the interested reader is referred to the original publication [29] or the WGCNA homepage: http://labs.genetics.ucla. edu/horvath/CoexpressionNetwork. As outlined in the materials and methods section, we constructed weighted, signed correlation networks from the pre-processed datasets. Next, we identified modules that correlated to disease stage (in the following referred to as correlation with HD). To this end, we converted the neuropathological stage assignment of the samples, as listed in the original publication [27], to a numerical scale with controls as 1, HD grade 0 as 2, HD grade 1 as 3 and so forth. 'Module eigengenes', which represent a summary for all genes within a module were computed and subsequently correlated with HD. Negative, or positive correlation indicates that the expression of the genes in a module is lower, or higher, respectively, in patient compared to control samples. From here on we focused only on significantly correlated 
modules (Benjamini-Hochberg corrected $P$-values $<0.05$ ). Using 'eigengene based connectivity' (kME) as a measure of gene co-expression strength in a particular module (weighted from 0 to 1 ), we identified the genes with the highest connectivity in a module (hub genes). We also analyzed the preservation of the significantly correlated modules in a particular network in the datasets of the other brain regions. Preservation can be seen as the similarity of co-expression between genes in a module, but also connectivity patterns of individual modules for the two data sets. Preservation was calculated using permutations of the preservation statistics and is represented by a Z-summary value. High preservation, or high Z-summary values indicate that modules are densely connected, distinct and reproducible. Z-summary values tend to be higher for larger modules, i.e. small modules are very often found to be only weakly preserved.

In the cerebellum dataset, 2504 genes (about 20.0\% of all genes in the dataset) were assigned in negatively correlated and 2230 genes (about $17.8 \%$ of all genes in the dataset) in positively correlated modules $\left(P_{\text {adj }}<0.05\right)$ (Figure 1A and $\mathrm{B}$ ). This is in marked contrast to what was found by Hodges and colleagues, who identified only 340 statistically significantly dysregulated probe sets, corresponding to 290 genes (HG-U133A chip; $P<0.001$ ). For gene ontology $(\mathrm{GO})$ enrichment and regulatory factor prediction of the modules in the cerebellum network see Table 1 . The eigengene based connectivity (kME) for all identified modules showed a significant linear positive or negative relationship with the gene significance for HD.

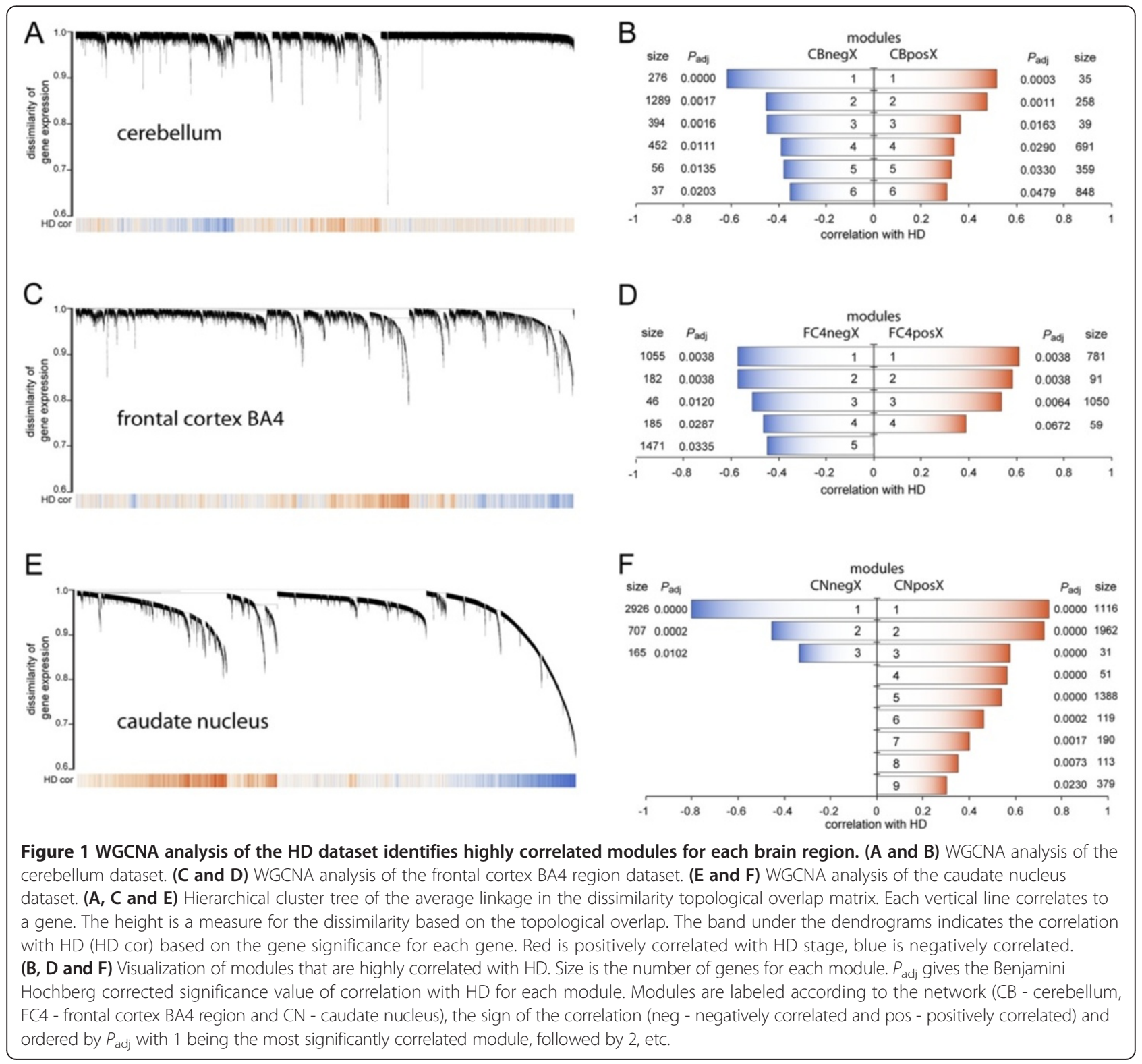


Table 1 Gene ontology enrichment for the cerebellum network

\begin{tabular}{|c|c|c|c|}
\hline Module & cor & GO-term (DAVID) & Potential regulators \\
\hline CBpos1 & up & metal binding/zinc-finger $(0.84,0.89)$ & $\begin{array}{l}\text { MYOD }(0.0314)^{2} \text {, ZIC2 }(0.0314)^{2} \text {, E2F1/E2F4 together } \\
\text { with DP1/DP2, or RB }(0.0314)^{2}, \text { NFY }(0.0314)^{2}\end{array}$ \\
\hline \multirow[t]{2}{*}{ CBpos2 } & \multirow[t]{2}{*}{ up } & DNA binding/zinc-finger $(3.97,0.003)$ & \multirow[t]{6}{*}{$\operatorname{miR} 124(0.054)^{1}$} \\
\hline & & chromatin binding/remodeling $(1.82,0.096)$ & \\
\hline CBpos3 & up & ubiquitin protein ligase binding $(1.1,0.49)$ & \\
\hline \multirow[t]{3}{*}{ CBpos4 } & \multirow[t]{3}{*}{ up } & metal binding/zinc-finger $(6.98,0.000)$ & \\
\hline & & chromatin modification $(4.8,0.004)$ & \\
\hline & & RNA binding/processing $(3.41,0.03)$ & \\
\hline \multirow[t]{3}{*}{ CBpos5 } & \multirow[t]{3}{*}{ up } & protein folding/chaperones $(6.77,0.000)$ & HSF1 $(0.09)^{1}$ \\
\hline & & chromatin assembly $(3.19,0.003)$ & \multirow{2}{*}{$\begin{array}{l}\text { HSF1 }(0.000)^{2}, \text { NRF1 }(0.001)^{2}, \text { USF1 }(0.001)^{2}, \\
\text { E4BP4 }(0.024)^{2}\end{array}$} \\
\hline & & mRNA processing $(2.95,0.034)$ & \\
\hline CBpos6 & up & metallothionein $(4.24,0.003)$ & $\begin{array}{l}\text { miR124 }(0.027)^{1} \text {, let7 }(0.027)^{1}, \text { sOX2 }(0.027)^{1} \text {, } \\
\text { MYOG }(0.027)^{1} \text {, HSF1 }(0.044)^{1}\end{array}$ \\
\hline CBneg1 & down & synapse $(2.14,0.33)$ & \\
\hline \multirow[t]{2}{*}{ CBneg2 } & \multirow[t]{2}{*}{ down } & mitochondrion $(10.44,0.000)$ & NRF1 $(0.108)^{1}$ \\
\hline & & proteasome $(3.13,0.000)$ & $\begin{array}{l}\text { E4F1 }(0.000)^{2}, \operatorname{PAX} 3(0.006)^{2}, \operatorname{ATF}(0.007)^{2}, \\
\text { ELK1 }(0.012)^{2}\end{array}$ \\
\hline CBneg3 & down & mitochondrion $(2.77,0.007)$ & $\begin{array}{l}\text { SF1 }(0.000)^{2}, \text { ERR1 }(0.001)^{2}, \text { PAX4 }(0.001)^{2}, \\
\text { TCF3 }(0.002)^{2}, \text { ZBTB14 }(0.046)^{2}\end{array}$ \\
\hline CBneg4 & down & mitochondrion $(2.85,0.005)$ & \\
\hline CBneg5 & down & endoplasmic reticulum $(1.02,0.95)$ & \\
\hline CBneg6 & down & cytoplasmic vesicle $(0.88,0.99)$ & \\
\hline $\mathrm{HTT}$ & down & mitochondrion $(5.3,0.000)$ & \\
\hline
\end{tabular}

Gene ontology (GO) enrichment for the HD cerebellum network. Genes in the identified modules were analyzed using DAVID. The sign of the correlation (cor) with HD and the over-represented GO-terms are shown. The first number in brackets after the GO-term is the respective fold enrichment, the second number the adjusted $P$-value, as determined by DAVID. All significantly enriched (adjusted $P<0.05$ ) GO-terms are shown. In cases where no significantly enriched GO-term was identified, the GO-term with the highest fold enrichment is shown. Potential regulators of a module were identified using ${ }^{1} \mathrm{GO}$-Elite, or ${ }^{2}$ WebGestalt. Adjusted $P$-values are given in brackets after the name. Regulators that were identified by both tools are highlighted in bold. HTT is part of the CBneg2 module in the cerebellum network. The GO-term enrichment for 100 genes with the highest correlation with HTT is shown.

Some genes exhibited high kME values and also high gene significance values indicating these genes are potential hub genes (Additional file 1A). The cerebellum modules CBpos5 and CBneg2 were highly preserved in both the frontal cortex and caudate nucleus. Modules CBpos4, CBpos5 and CBneg4 were better preserved in the frontal cortex, than in the caudate nucleus dataset (Figure 2A and $\mathrm{B}$ ). Figure $3 \mathrm{~A}$ and $\mathrm{B}$ illustrate the connectivity between the top 50 hub genes for the CBpos5 and CBneg2 modules (see also Additional file 2). 33 (66\%) of the top 50 hub genes of the CBneg1 module were also statistically significantly dysregulated, as determined by Hodges and colleagues. Additionally, only modules CBneg2 (15/50 = $30 \%)$ and CBneg3 $(14 / 50=28 \%)$ showed considerable overlap of module hub genes and dysregulated genes. In total, $46(15.9 \%)$ of the statistically significantly dysregulated genes were not sorted into modules that were correlated with HD. The CBneg1 module is highly negatively correlated with HD (Figure 1B), but GO analysis showed no significant enrichment (Table 1). However, in depth analysis of the molecular function of the hub genes in this module revealed several genes involved in synaptic function. For example $C B L N 1$ is a cerebellum specific precursor of cerebellin, which is enriched in the post-synapses of Purkinje cells. Further neuronal related hub genes were SLC17A7, SCN1B and PDE10A. The other modules that were negatively correlated with $\mathrm{HD}$ in cerebellum are highly enriched for mitochondrial and proteasomal genes, indicating an attenuated function of these two processes (Figure 3A, Additional file 2 and Table 1). The positively correlated cerebellum modules are enriched for transcriptional regulation, chromatin binding/remodeling/modification, RNA binding/processing and metallothioneins (Table 1). Analysis of the CBpos5 module revealed a very high enrichment in protein folding/chaperone genes, as well as chromatin assembly and mRNA processing genes (Table 1). Intriguingly, 14 of the top 50 hub genes of the CBpos5 module are involved in protein folding, all of which share very high connectivity (Figure 3A). Notably, there was no indication that genes involved in inflammation or the immune response are correlated with HD in the cerebellum. 

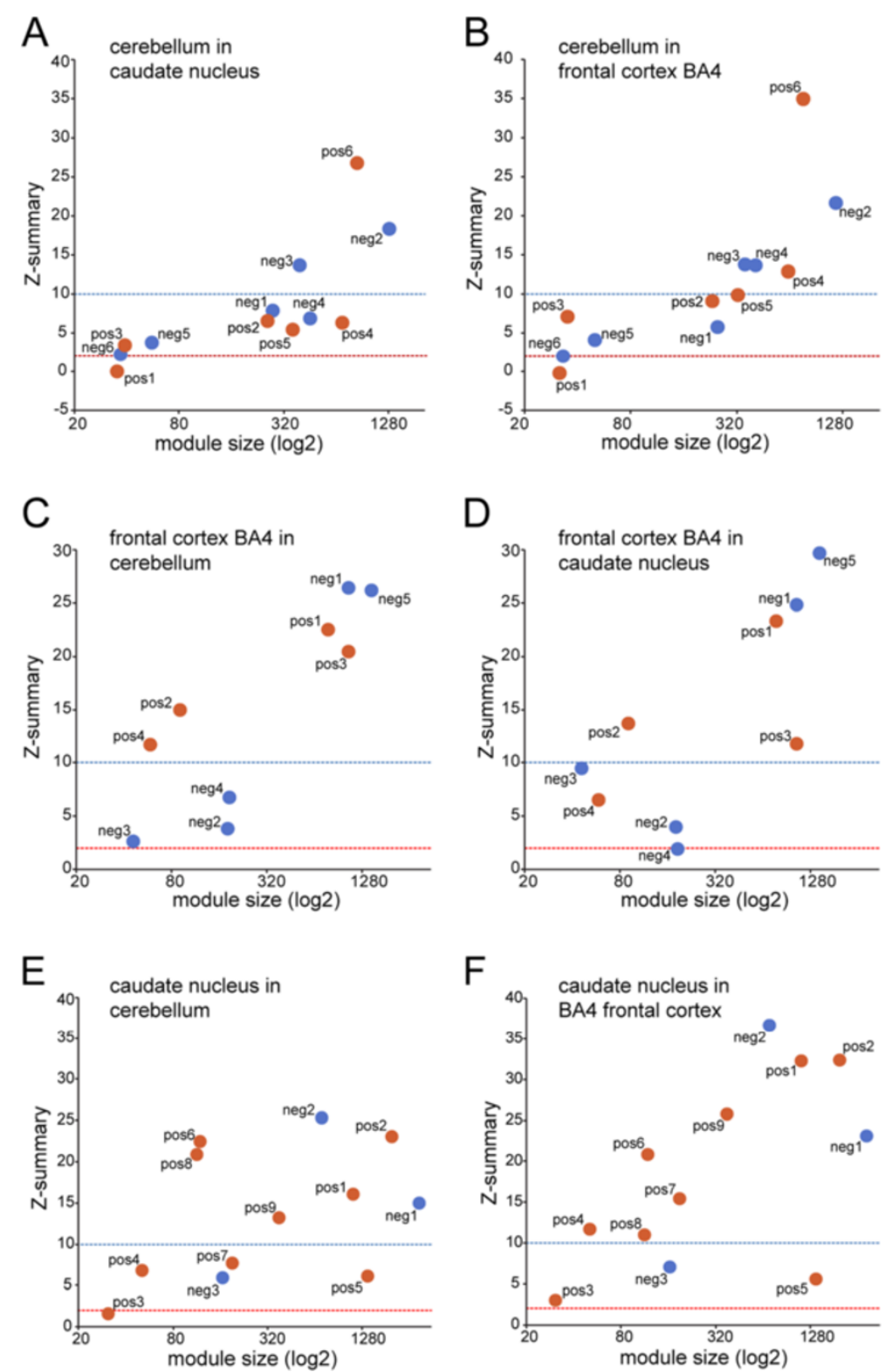

Figure 2 Preservation analysis shows only few tissue specific modules. The Z-summary is a measure for module preservation. Values less than 2 (red lines) indicate no preservation, between 2 and 10 (blue lines) module structures are preserved and above 10 the module structure is highly preserved. Preservation analysis of cerebellum modules in the caudate nucleus (A) and frontal cortex BA4 region dataset (B). Preservation analysis of frontal cortex BA4 region modules in the cerebellum (C) and caudate nucleus dataset (D). Preservation analysis of caudate nucleus modules in the cerebellum $\mathbf{( E )}$ and frontal cortex BA4 region dataset $\mathbf{( F )}$.

We could not identify any significantly correlated modules in the frontal cortex BA9 region dataset, the same result as obtained by Hodges and co-workers (data not shown). By contrast, we found significant changes in the BA4 region of the frontal cortex (Figure $1 \mathrm{C}$ and D). Here, 2939 (23.5\%) genes were assigned to negatively and $1981(15.8 \%)$ genes to positively correlated modules $\left(P_{\text {adj }}<0.05\right)$ (Figure 1D). For gene ontology (GO) enrichment and regulatory factor prediction of the modules in the frontal cortex BA4 region network see Table 2. As for the cerebellum network, the modules showed significant linear relationships between eigengene connectivity and gene significance for HD (Additional file 1B). Preservation analysis indicated that most frontal cortex BA4 region modules were equally well preserved in the caudate nucleus, or cerebellum dataset, respectively (Figure 2C and D). However, the FC4neg3 module was slightly less preserved in cerebellum, compared to caudate nucleus; modules FC4pos3, FC4pos4 and FC4neg4 were slightly better preserved in cerebellum (Figure $2 \mathrm{C}$ and D). Module 


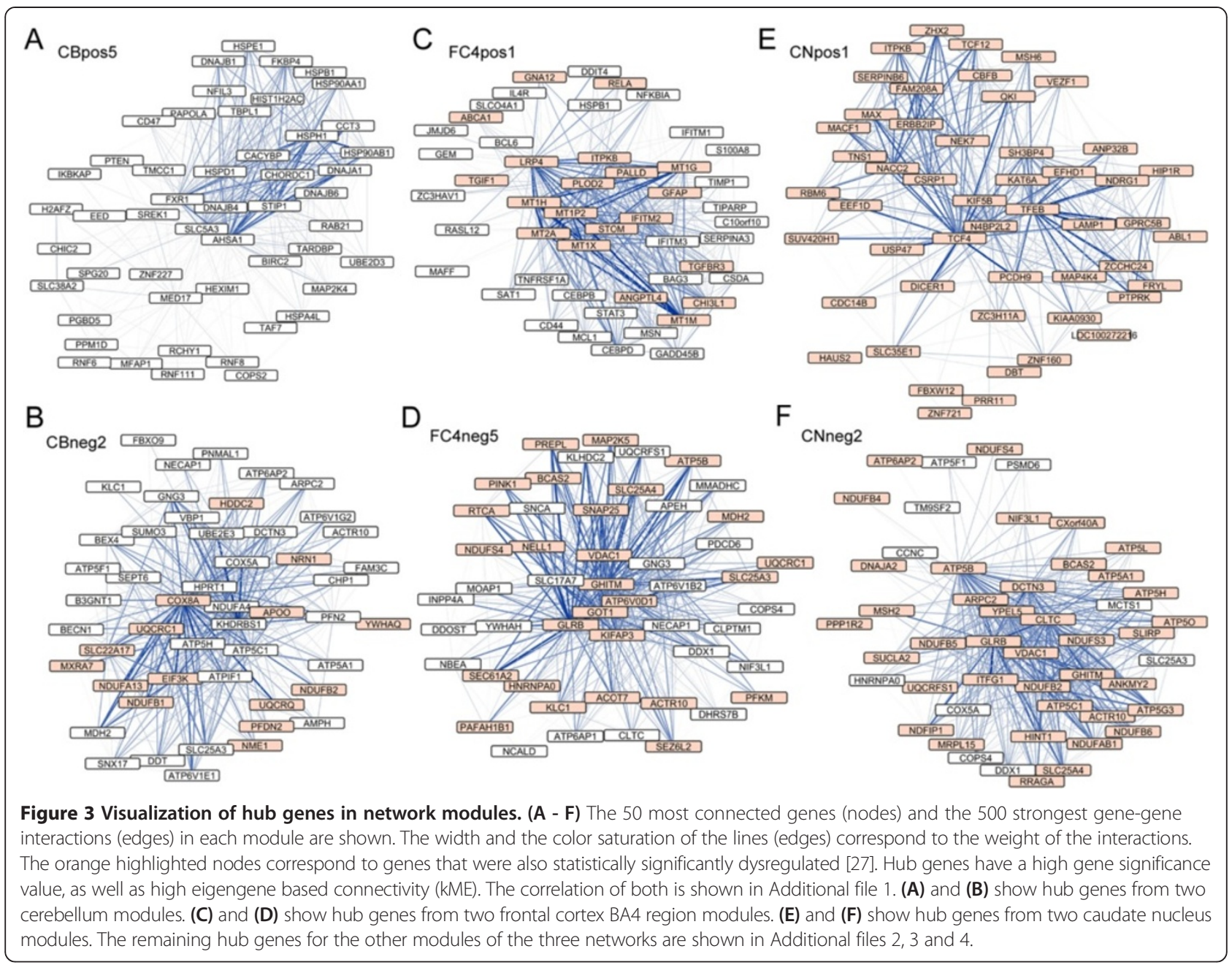

FC4pos4, although it was just short of being significantly correlated with HD ( $\left.P_{\text {adj }}=0.064\right)$ (Figure 1D), is, like the CBpos5 module in the cerebellum network, highly enriched for protein folding/chaperone genes (Tables 1 and 2, Additional file $3 \mathrm{C}$ and Figure 4F). The GO enrichment analysis of the other positively correlated modules more or less mirrored the cerebellum network with the exception of a high enrichment for inflammatory response and $\mathrm{NF \kappa B} / \mathrm{I} \kappa \mathrm{B}$ genes in the FC4pos1 module (Table 2). This finding was further supported by the fact that several transcription factors, which regulate immune response/ inflammatory pathways, were identified as hub genes (Figure 3C). Amongst these were CEBPB, CEBPD, BCL6, MT1G, NFKBIA, IFITM1, IFITM2, IFITM3, S100A8, IL4R and TNFRSF1A. The FC4pos1 module was also enriched for genes implicated in angiogenesis, e.g. SAT1, ANGPTL4 and JMJD6 (Table 2 and Figure 3C). Notably, as for cerebellum, none of the negatively correlated modules was significantly enriched for synaptic/neuronal genes (Table 2). However, hub gene analysis of the FC4neg1 module (GO enrichment for synapse $1.86, P_{\text {adj }}=0.063$ ) showed several genes involved in synaptic/neuronal function (GABRG2, SCN2B, RASGRF1, KCNJ9, GRIN2A, NRXN1, GPR176) (Additional file $3 \mathrm{D}$ ). Again, as in cerebellum, mitochondrial and proteasomal genes were negatively correlated with HD. Furthermore, genes implicated in protein transport, glycolysis and another set of protein folding/ chaperone genes were assigned to negatively correlated modules (Table 2). The overlap of hub genes and statistically significantly dysregulated genes as determined by Hodges and colleagues was as follows: FC4pos1 20 of $49=$ 40.8\%; FC4pos2 3 of $50=6.0 \%$; FC4pos3 38 of $44=86.4 \%$; FC4pos 41 of $50=2.0 \%$; FC4neg1 28 of $50=56.0 \%$; FC4neg2 10 of $50=20 \%$; FC4neg3 10 of $45=22.2 \%$; FC4neg4 3 of $50=6.0 \%$; FC4neg 528 of $50=56.0 \%$. In total, 217 (28.9\% of 750 genes) of the significantly dysregulated genes in the frontal cortex BA4 region were not sorted into modules that were correlated with HD.

As in the original publication, we observed the largest changes in the caudate nucleus (compare Figure 1A, C and E), with 3798 (30.4\%) genes assigned to negatively and $5349(42.8 \%)$ genes assigned to positively correlated 
Table 2 Gene ontology enrichment for the frontal cortex (BA4 region) network

\begin{tabular}{|c|c|c|c|}
\hline Module & cor & GO-term (DAVID) & Potential regulators \\
\hline \multirow[t]{7}{*}{ FC4pos1 } & \multirow[t]{7}{*}{ up } & inflammatory response $(6.64,0.000)$ & $\operatorname{MEF} 2(0.041)^{1}, \operatorname{NFkB}(0.041)^{1}, \operatorname{miR3} 4(0.050)^{1}$, let7 $(0.041)^{1}$ \\
\hline & & metallothionein $(4.02,0.04)$ & \multirow[t]{6}{*}{ STAT3 $(0.005)^{2}$, STAT5B $(0.005)^{2}, J U N(0.040)^{2}$} \\
\hline & & regulation of transcription $(3.58,0.018)$ & \\
\hline & & regulation of apoptosis $(3.25,0.02)$ & \\
\hline & & vasculature development $(2.7,0.021)$ & \\
\hline & & cation homeostasis $(2.68,0.014)$ & \\
\hline & & IKB/NFKB $(2.65,0.02)$ & \\
\hline FC4pos2 & up & RNA binding/splicing $(2.36,0.037)$ & $\begin{array}{l}\text { E2F }(0.006)^{2}, \operatorname{TLX} 2(0.006)^{2}, \mathrm{XBP} 1(0.008)^{2}, \mathrm{YY} 1(0.011)^{2} \\
\text { HSF1 }(0.021)^{2}, \text { LEF1 }(0.021)^{2}, \mathrm{MYC}(0.021)^{2} \\
\text { SOX5 }(0.025)^{2}, \text { AR }(0.031)^{2}\end{array}$ \\
\hline \multirow[t]{2}{*}{ FC4pos3 } & \multirow[t]{2}{*}{ up } & amino acid catabolic process $(5.52,0.005)$ & $\operatorname{miR} 155(0.018)^{1}$ \\
\hline & & fatty acid metabolism $(3.25,0.011)$ & MEF2 $(0.038)^{2}$ \\
\hline \multirow[t]{2}{*}{ FC4pos4 } & \multirow[t]{2}{*}{ up } & \multirow[t]{2}{*}{ protein folding/chaperones $(3.75,0.001)$} & miR1 $(0.009)^{1}$, HSF1 $(0.009)^{1}$ \\
\hline & & & $\begin{array}{l}\text { HSF1 }(0.000)^{2}, \mathrm{NFIL} 3(0.033)^{2}, \mathrm{STAT1}(0.037)^{2} \\
\text { SF1 }(0.037)^{2}, \mathrm{NFY}(0.039)^{2}\end{array}$ \\
\hline FC4neg1 & down & protein transport $(2.07,0.03)$ & \multirow[t]{5}{*}{$\operatorname{EVI1}(0.011)^{2}, \operatorname{E4F1}(0.045)^{2}, \mathrm{XBP} 1(0.045)^{2}, \operatorname{ATF} 2(0.045)^{2}$} \\
\hline FC4neg2 & down & membrane proteins $(1.49,0.2)$ & \\
\hline FC4neg3 & down & fibronectin $(1.6,0.84)$ & \\
\hline \multirow[t]{3}{*}{ FC4neg4 } & \multirow[t]{3}{*}{ down } & zinc-finger $(1.74,0.84)$ & \\
\hline & & mitochondrion $(6.01,0.000)$ & \\
\hline & & proteasome/ubiquitin system $(5.01,0.000)$ & NRF1 $(0.036)^{1}$ \\
\hline \multirow[t]{3}{*}{ FC4neg5 } & \multirow[t]{3}{*}{ down } & glycolysis $(3.5,0.001)$ & \multirow{3}{*}{$\begin{array}{l}\text { ELK1 }(0.000)^{2}, \text { SP1 }(0.000)^{2}, \text { SF1 }(0.001)^{2}, \text { E4F1 }(0.001)^{2} \\
\text { TCF11 } \\
\text { NRF1 }(0.005)^{2}, \text { ATF }(0.007)^{2}, \text { CREB }(0.028)^{2}\end{array}$} \\
\hline & & protein folding/chaperones $(3.04,0.015)$ & \\
\hline & & protein transport $(3.0,0.002)$ & \\
\hline $\mathrm{HTT}$ & n.a. & \multicolumn{2}{|l|}{ cytoskeleton $(1.43,0.18)$} \\
\hline
\end{tabular}

modules $\left(P_{\text {adj }}<0.05\right)$ (Figure $\left.1 \mathrm{~F}\right)$. While the correlation of modules in the cerebellum and frontal cortex BA4 networks was largely comparable, the correlation of the caudate nucleus modules was higher, highlighting the prominent pathology in the striatum of HD patients (compare Figure 1B, D and F). For gene ontology (GO) enrichment and regulatory factor prediction of the modules in the caudate nucleus network see Table 3. We again observed a very strong linear relationship between the eigengene based connectivity and the gene significance for HD, indicating approximate scale free topology of the network and existence of hub genes (Additional file $1 C$ ). Overall, preservation of caudate nucleus modules was better in the frontal cortex (BA4) than in cerebellum (Figure 2E and F). Again, this finding most probably reflects the degree of pathology in the different tissues. The CNpos6 module was the only module that was equally well preserved in both cerebellum and frontal cortex BA4. This module is highly enriched for inflammatory response genes (Table 3 ). The CNpos5 module seems to be caudate nucleus specific, as it was only weakly preserved in both, cerebellum and frontal cortex BA4 despite being a rather large module with 1388 genes. GO analysis showed enrichment for cilium related genes (Table 3), while the hub genes were enriched for genes involved in extracellular matrix organization, e.g. CYR61, CSGALNACT1, ANXA2, AGT, COL21A1, EFEMP1 and ECM2 (Additional file 4D). The highly negatively correlated CNneg1 module was enriched for genes involved in neuronal function, especially for genes involved in synaptic function/plasticity and ion channels (Table 3). This finding was reflected in the hub gene analysis of the CNneg1 module, in which about $50 \%$ of the identified hub genes are implicated to play a role in synaptic function (Additional file 4I). Furthermore, all CNneg1 hub genes were statistically significantly dysregulated as 


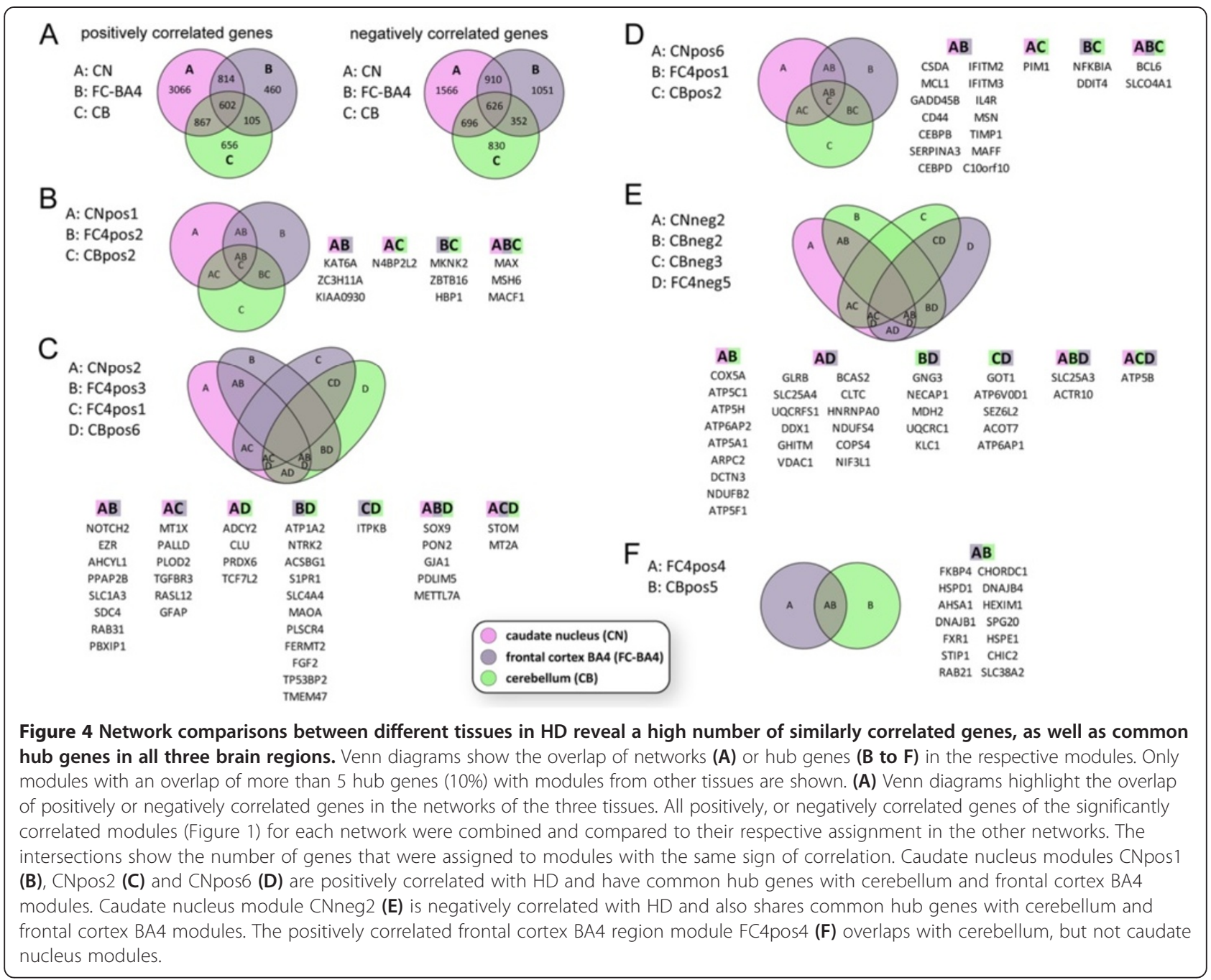

determined by Hodges and co-workers. The CNneg2 module represented the negatively correlated gene clusters, like e.g. mitochondrial and proteasomal genes, which we also observed in cerebellum and frontal cortex (Tables 1, 2, 3 and Figure 4E). In addition, this module was enriched for chaperone and spliceosome genes and genes required for DNA repair and translation initiation (Table 3). Consequently, also its hub genes were mostly enriched for mitochondrial genes (Figure 3F). Modules that were positively correlated with HD in the caudate nucleus network were, amongst others, enriched for transcriptional regulators, chromatin modifiers and genes involved in mRNA processing (modules CNpos1 and CNpos2, Table 3). Especially genes functioning in the development of blood vessel, glial cells, epithelial cells and astrocytes clustered in the hub genes of the CNpos2 module (Additional file 4A). Also, all hub genes in the CNpos1 and CNpos2 modules were statistically significantly dysregulated [27] (Figure 3E and Additional file 4A). Hub gene and GO analysis showed a very high enrichment for inflammatory response/immune system genes in the CNpos6 and CNpos 8 modules (Table 3 and Additional file 4E and $\mathrm{G}$ ). Noteworthy, 6 complement genes $(C 1 R, C 1 S, C 1 Q A$, $C 1 Q B, C 3$ and $C 5 A R 1)$ were assigned hub gene status in these modules including the central component $\mathrm{C} 3$ (Additional file 4G). However, only C3 was previously found to be significantly dysregulated (Additional file $4 \mathrm{E}$ and G). The caudate nucleus network fit the analysis by Hodges and colleagues very well, as in total only 193 (5.0\% of 3825 genes) of the significantly dysregulated genes were not sorted into modules that were correlated with HD.

\section{Comparison of the three human brain region networks}

To investigate the similarity of transcriptional dysregulation between tissues, we compared the significantly positively and negatively correlated genes in the three networks (Figure 4A), as well as the conservation of hub genes (Figure 4B-F). Using the caudate nucleus network as the basis, we found that both cerebellum and frontal 
Table 3 Gene ontology enrichment for the caudate nucleus network

\begin{tabular}{|c|c|c|c|}
\hline Module & cor & GO-term (DAVID) & Potential regulators \\
\hline \multirow[t]{3}{*}{ CNpos1 } & \multirow[t]{3}{*}{ up } & regulation of transcription $(6.18,0.000)$ & \multirow{3}{*}{$\begin{array}{l}\text { YY1 }(0.000)^{2}, \text { ELK1 }(0.001)^{2}, \text { GABPB1 }(0.002)^{2}, \\
\text { SP1 }(0.002)^{2} \text {, NRF1 }(0.002)^{2}, \text { E2F }(0.007)^{2}, \text { IRF1 }(0.011)^{2}, \\
\text { GTF3A }(0.032)^{2}, \text { SOX9 }(0.033)^{2}\end{array}$} \\
\hline & & chromatin modification $(3.85,0.003)$ & \\
\hline & & mRNA processing $(3.71,0.004)$ & \\
\hline \multirow[t]{3}{*}{ CNpos2 } & \multirow[t]{3}{*}{ up } & regulation of transcription $(5.94,0.001)$ & \multirow[t]{3}{*}{ NFAT $(0.004)^{2}$} \\
\hline & & cell migration $(4.09,0.004)$ & \\
\hline & & lipid metabolism $(2.51,0.001)$ & \\
\hline CNpos3 & up & RNA binding $(0.65,1.0)$ & \\
\hline CNpos4 & up & chromatin organization $(2.45,0.008)$ & $\begin{array}{l}\text { EGR2 }(0.010)^{2}, \text { MYC }(0.040)^{2}, \text { TCF3 }(0.040)^{2}, \operatorname{NR} 2 F 2(0.040)^{2}, \\
\text { TCF12 }(0.040)^{2}, \text { SP1 }(0.040)^{2}, \text { EGR1 }(0.040)^{2}, \text { EGR4 }(0.040)^{2}\end{array}$ \\
\hline CNpos5 & up & cilium $(2.79,0.003)$ & \\
\hline CNpos6 & up & inflammatory response $(8.33,0.000)$ & $\begin{array}{l}\text { STAT5A }(0.000)^{2}, \text { STAT3 }(0.000)^{2}, \text { STAT5B }(0.000)^{2}, \\
\text { BACH2 }(0.002)^{2}, \text { NFAT }(0.005)^{2}, \text { JUN }(0.020)^{2}, \text { NFE2 }(0.035)^{2}\end{array}$ \\
\hline CNpos7 & up & regulation of transcription $(3.0,0.045)$ & \\
\hline \multirow[t]{2}{*}{ CNpos8 } & \multirow[t]{2}{*}{ up } & inflammatory response $(14.15,0.000)$ & \multirow[t]{2}{*}{ ELF1 $(0.000)^{2}$, STAT1/STAT2 $(0.017)^{2}$, IRF1 $(0.017)^{2}$} \\
\hline & & icosanoid metabolism $(1.73,0.001)$ & \\
\hline \multirow[t]{2}{*}{ CNpos9 } & \multirow[t]{2}{*}{ up } & myelination $(3.06,0.002)$ & \\
\hline & & oligodendrocyte/glial differentiation $(2.4,0.054)$ & \\
\hline \multirow[t]{5}{*}{ CNneg1 } & \multirow[t]{5}{*}{ down } & synapse $(12.23,0.000)$ & \multirow{5}{*}{$\begin{array}{l}\text { miR16 }(0.018)^{1}, \text { NRF1 }(0.03)^{1} \text { REST }(0.000)^{2}, \text { EGR1 }(0.000)^{2}, \\
\text { SF1 }(0.000)^{2}, \text { CREB1 }(0.000)^{2}, \text { JUN }(0.000)^{2}, \text { EGR4 }(0.000)^{2}, \\
\text { MYOD1 }(0.000)^{2}, \text { TCF3 }(0.000)^{2}, \text { RORA }(0.000)^{2}, \text { ATF1 }(0.000)^{2}, \\
\text { E4F1 }(0.000)^{2}, \text { SP1 }(0.000)^{2}, \text { ESRRA }(0.001)^{2}, \text { TCF1 }(0.002)^{2}, \\
\text { PAX4 }(0.002)^{2}, \text { TFAP4 }(0.003)^{2}, \text { MAZ }(0.003)^{2}, \text { HAND1 }(0.006)^{2}, \\
\text { EGR2 }(0.007)^{2}, \text { NRF2 }(0.007)^{2}, \text { ATF3 }(0.008)^{2}, \text { RFX1 }(0.008)^{2}, \\
\text { POU3F1 }(0.008)^{2}, \text { LEF1 }(0.011)^{2}, \text { POU1F1 }(0.019)^{2}, \text { MYB }(0.027)^{2}, \\
\text { TCF12 }(0.041)^{2}, \text { NFE2 }(0.041)^{2}, \text { MEIS1 }(0.044)^{2}, \text { SREBF1 }(0.050)^{2}\end{array}$} \\
\hline & & ion channels $(4.61,0.000)$ & \\
\hline & & regulation of synaptic plasticity $(4.58,0.000)$ & \\
\hline & & protein transport $(2.89,0.011)$ & \\
\hline & & protein targeting to mitochondrion $(2.75,0.007)$ & \\
\hline \multirow[t]{7}{*}{ CNneg2 } & \multirow[t]{7}{*}{ down } & mitochondrion $(20.31,0.000)$ & \multirow[t]{7}{*}{ YY1 $(0.005)^{1}$, ETS1 $(0.005)^{1}, \operatorname{NRF} 1(0.005)^{1}$ ELK1 $(0.000)^{2}$} \\
\hline & & proteasome/protein catabolic process $(5.83,0.000)$ & \\
\hline & & mitochondrial ribosome $(4.54,0.000)$ & \\
\hline & & chaperones $(3.17,0.012)$ & \\
\hline & & spliceosome $(3.0,0.002)$ & \\
\hline & & DNA repair $(2.47,0.027)$ & \\
\hline & & translation initiation $(1.95,0.007)$ & \\
\hline CNneg3 & down & hemoglobin complex $(1.74,0.024)$ & \\
\hline $\mathrm{HTT}$ & down & neuron projection $(1.93,0.56)$ & \\
\hline
\end{tabular}

Gene ontology (GO) enrichment for the caudate nucleus network. Genes in the identified modules were analyzed using DAVID. The sign of the correlation (cor) with HD and the over-represented GO-terms are shown. The first number in brackets after the GO-term is the respective fold enrichment, the second number the adjusted $P$-value, as determined by DAVID. All significantly enriched (adjusted $P<0.05$ ) GO-terms are shown. In cases where no significantly enriched GO-term was identified, the GO-term with the highest fold enrichment is shown. Potential regulators of a module were identified using ${ }^{1} \mathrm{GO}-\mathrm{Elite}$, or ${ }^{2}$ WebGestalt. Adjusted $P$-values are given in brackets after the name. Regulators that were identified by both tools are highlighted in bold. HTT is part of the CNneg1 module in the caudate nucleus network. The GO-term enrichment for 100 genes with the highest correlation with HTT is shown.

cortex BA4 networks exhibited considerable similarities of significantly correlated genes (Figure 4A). More than 1200 genes were correlated in the same way in all three brain regions; the correlations of 1563 genes were conserved between caudate nucleus and frontal cortex BA4 and 1724 genes were similarly correlated in caudate nucleus and cerebellum (Figure 4A). Gene ontology enrichment analysis showed that metallothioneins and genes involved in the stress response and angiogenesis were commonly positively correlated with $\mathrm{HD}$ in all three networks (Table 4). Genes implicated in mitochondrial function, glycolysis, intracellular protein transport, proteasome and synaptic vesicles were commonly negatively correlated with HD in all three networks (Table 4). Furthermore, we found extensive conservation of hub genes in modules that were positively correlated with HD (Figure 4B to D). However, only one set of modules, which were negatively correlated with $\mathrm{HD}$, exhibited common hub genes (Figure 4E). Interestingly, the CNneg1 module of the caudate nucleus network, which represented the 
Table 4 Gene ontology enrichment for conserved genes between HD networks

\begin{tabular}{|c|c|c|}
\hline Overlap & GO-term (DAVID) & Potential regulators \\
\hline \multicolumn{3}{|c|}{ Positively correlated genes } \\
\hline \multirow[t]{2}{*}{$\mathrm{CN}$ and $\mathrm{FC}-\mathrm{BA} 4$} & inflammatory response $(5.6,0.001)$ & \multirow[t]{5}{*}{ MYC/MAX $(0.010)^{2}$, STAT3 $(0.010)^{2}$, ETS2 $(0.020)^{2}$} \\
\hline & epithelial to mesenchymal transition $(1.18,0.026)$ & \\
\hline \multirow[t]{3}{*}{$\mathrm{CN}$ and $\mathrm{CB}$} & regulation of transcription $(5.2,0.000)$ & \\
\hline & mRNA processing $(3.69,0.001)$ & \\
\hline & apical junction complex $(1.91,0.027)$ & \\
\hline FC-BA4 and CB & zinc-finger $(1.17,0.44)$ & \\
\hline \multirow[t]{3}{*}{ all three networks } & metallothionein $(5.1,0.000)$ & \multirow{3}{*}{$\begin{array}{l}\text { FOXF2 }(0.002)^{2}, \mathrm{NFIL3}(0.010)^{2}, \mathrm{LEF} 1(0.017)^{2}, \mathrm{HSF} 1(0.017)^{2} \\
\text { ATF2 }(0.022)^{2}, \mathrm{HIF1A}(0.026)^{2}, \mathrm{SP1}(0.042)^{2}\end{array}$} \\
\hline & stress response/chaperones $(2.62,0.02)$ & \\
\hline & angiogenesis $(2.61,0.039)$ & \\
\hline \multicolumn{3}{|c|}{ Negatively correlated genes } \\
\hline \multirow[t]{3}{*}{$\mathrm{CN}$ and $\mathrm{FC}-\mathrm{BA} 4$} & synaptic transmission $(4.8,0.000)$ & \multirow{3}{*}{$\begin{array}{l}\text { REST }(0.004)^{2}, \text { EGR4 }(0.015)^{2}, \text { SP1 }(0.015)^{2}, \text { ATF1 }(0.022)^{2}, \\
\text { MEIS1 }(0.022)^{2}, \text { ELK1 }(0.022)^{2}, \text { ESRRA }(0.040)^{2}, \text { ATF3 }(0.046)^{2}, \\
\text { E4F }(0.046)^{2}, \text { SF1 }(0.046)^{2}, \text { LEF1 }(0.046)^{2}\end{array}$} \\
\hline & ion channels $(4.65,0.000)$ & \\
\hline & protein catabolic process $(4.23,0.008)$ & \\
\hline \multirow[t]{3}{*}{$\mathrm{CN}$ and $\mathrm{CB}$} & mitochondrion $(8.46,0.000)$ & \multirow[t]{3}{*}{ SF1 $(0.002)^{2}$, E4F $(0.020)^{2}$} \\
\hline & intracellular protein transport $(3.02,0.023)$ & \\
\hline & vesicle mediated transport $(2.19,0.013)$ & \\
\hline FC-BA4 and CB & coenzyme metabolic process $(1.86,0.98)$ & $\operatorname{ELK1}(0.007)^{2}, \operatorname{E4F}(0.007)^{2}$ \\
\hline \multirow[t]{5}{*}{ all three networks } & mitochondrion $(6.01,0.000)$ & \multirow{5}{*}{$\begin{array}{l}\text { CREB }(0.000)^{2}, \text { ATF3 }(0.001)^{2}, \text { SF1 }(0.015)^{2}, \text { ERR1 }(0.015)^{2}, \\
\text { TCF11 }(0.015)^{2}, \text { ELK1 }(0.018)^{2}, \text { ATF4 }(0.018)^{2}, \text { SREBF1 }(0.018)^{2}, \\
\text { ATF6 }(0.019)^{2}, \text { E4F }(0.024)^{2}, \text { JUN }(0.026)^{2}, \text { EGR1 }(0.039)^{2}, \text { NRF1 }(0.049)\end{array}$} \\
\hline & glycolysis $(2.74,0.003)$ & \\
\hline & intracellular protein transport $(2.59,0.028)$ & \\
\hline & proteasome $(1.97,0.001)$ & \\
\hline & synaptic vesicle $(1.82,0.018)$ & \\
\hline
\end{tabular}

Gene ontology (GO) enrichment for conserved genes between HD networks. Genes were analyzed using DAVID and the over-represented GO-terms are shown. The first number in brackets after the GO-term is the respective fold enrichment, the second number the adjusted $P$-value, as determined by DAVID. All significantly enriched (adjusted $P<0.05$ ) GO-terms are shown. In cases where no significantly enriched GO-term was identified, the GO-term with the highest fold enrichment is shown. Potential regulators of a module were identified using ${ }^{1} \mathrm{GO}$-Elite, or ${ }^{2}$ WebGestalt. Adjusted $P$-values are given in brackets after the name.

"neuron/synaptic" module had only 7 hub genes overlap within several cerebellum modules and only 3 hub genes overlap in the frontal cortex BA4 region network, indicating its tissue specific character (data not shown). The CBpos5 cerebellum module and the FC4pos4 frontal cortex BA4 module were both enriched for chaperone genes (Tables 1 and 2). Consequently, we identified many chaperone genes, which had hub gene status in both networks (Figure 4F).

\section{Meta analysis of the caudate nucleus network with other disorders}

Next, we analyzed the preservation of the caudate nucleus network modules in gene expression datasets of other disorders (Figure 5). We used our caudate nucleus network, which was derived from the most affected brain tissue in HD and compared it to other highly affected tissues (Table 5). In addition to other neurodegenerative disorders (Alzheimer's disease (AD), amyotrophic lateral sclerosis (ALS), multiple sclerosis (MS), Parkinson's disease (PD) and schizophrenia (SCHIZ)), we also included muscle related diseases (myotonic dystrophy type 1/type 2 (DM1, DM2) and Duchenne Muscular Dystrophy (DMD)), dilated cardiomyopathy (DCM) and cancers (renal cell carcinoma (RCC) and ganglioglioma (GG)). When we analyzed the preservation of the caudate nucleus modules [27] in another HD dataset (HD-II) [35], we observed very high Z-summary scores for most modules, indicating a good reproducibility and thus robustness of the HD networks. The CNpos3 and CNpos4 modules were only assigned a few genes (Figure 1F), which most probably was the reason for their low preservation score (Figure 5A). The CNpos7 and CNneg3 modules had an average number of genes assigned to them. However, they appeared to be rather dataset specific, as we generally observed low Zsummary scores (Figure 5A). Other diseases that result in pronounced neurodegeneration, e.g. AD, ALS, MS, PD, SCHIZ or GG also exhibited high preservation scores for most modules. As controls for our preservation analysis we used the RCC, DMD and DCM data. In these datasets, Z-summary scores were low, apart from the two "inflammatory" modules CNpos6 and CNpos8, which were highly 


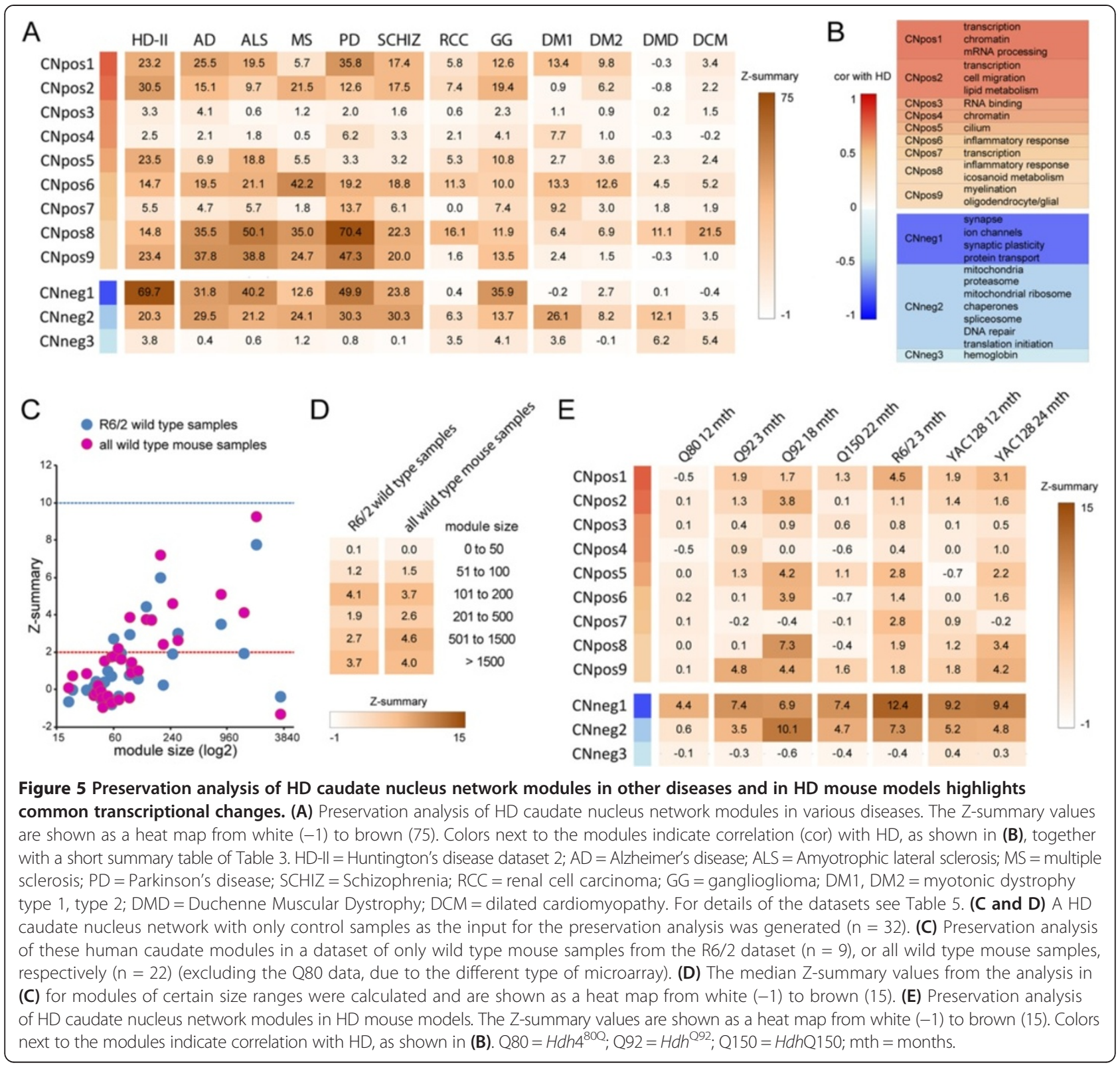

preserved in virtually all datasets (Figure 5A and B). Interestingly, the highest correlated (with HD) modules CNpos1 and CNneg1 showed only moderate preservation in MS. However, the two "inflammatory" modules again were very highly preserved between the HD and MS datasets (Figure 5A). For the muscle wasting disease myotonic dystrophy, type 1 showed higher preservation scores than type 2 . But notably both were characterized by a lack of preservation of the CNneg1 "neuron/synaptic" module, yet high preservation of the CNneg2 and CNpos1 modules (Figure 5A and B). This finding once more highlights the aforementioned successful separation of the synaptic/neuronal (CNneg1) transcriptional dysregulation from the more ubiquitous dysregulated genes (CNneg2) in our networks.

\section{Meta analysis of the caudate nucleus network with mouse models of HD}

Many models of HD exist, amongst which the murine models are the best studied [36,37]. However only limited data on transcriptome wide dysregulation is publicly available and the cross-species comparison additionally complicates meta analyses. To gain a first impression how the species comparison might affect the preservation analysis we compared only the caudate nucleus samples from control subjects with the wild type striatum 
Table 5 Microarray datasets used in this study

\begin{tabular}{|c|c|c|c|c|c|c|}
\hline Set & Accession & ctr/patient & Tissue & Array & Overlap & Reference \\
\hline \multirow[t]{4}{*}{ main $\mathrm{HD}$} & \multirow[t]{4}{*}{ GSE3790 } & $26 / 38$ & cerebellum & \multirow[t]{4}{*}{ GPL96 } & \multirow[t]{4}{*}{$100 \%$} & \multirow[t]{4}{*}[27]{} \\
\hline & & $16 / 18$ & BA4 region of frontal cortex & & & \\
\hline & & $12 / 18$ & BA9 region of frontal cortex & & & \\
\hline & & $32 / 36$ & caudate nucleus & & & \\
\hline$A D$ & \multirow[t]{6}{*}{ GSE26927 } & $7 / 11$ & entorhinal cortex & \multirow[t]{6}{*}{ GPL6255 } & \multirow[t]{6}{*}{$94.2 \%$} & \multirow[t]{6}{*}[35]{} \\
\hline ALS & & $9 / 10$ & cervical spinal cord & & & \\
\hline HD-II & & $10 / 9$ & ventral head of the caudate nucleus & & & \\
\hline MS & & $10 / 8$ & superior frontal gyri & & & \\
\hline PD & & $8 / 12$ & substantia nigra & & & \\
\hline $\mathrm{SCHIZ}$ & & $8 / 9$ & temporal cortex left, BA22 region & & & \\
\hline DM1 & \multirow[t]{2}{*}{ GSE7014 } & $5 / 10$ & skeletal muscle & \multirow[t]{2}{*}{ GPL570 } & \multirow[t]{2}{*}{$100 \%$} & \multirow[t]{2}{*}{ [81] } \\
\hline DM2 & & $5 / 20$ & skeletal muscle & & & \\
\hline $\mathrm{DMD}$ & GSE6011 & $14 / 22$ & quadriceps muscle & GPL96 & $100 \%$ & {$[82]$} \\
\hline DCM & GSE3585 & $5 / 7$ & heart & GPL96 & $100 \%$ & [83] \\
\hline $\mathrm{RCC}$ & GSE781 & $5 / 12$ & kidney & GPL96 & $100 \%$ & [84] \\
\hline GG & E-MEXP-1690 & $6 / 6$ & brain & GPL96 & $100 \%$ & {$[85]$} \\
\hline Set & Accession & WT/HD & Tissue & Array & Overlap & Reference \\
\hline Q80 & GSE10263 & $3 / 3$ & striatum & GPL81 & $51.2 \%$ & {$[28]$} \\
\hline Q150 & GSE10263 & $4 / 4$ & striatum & GPL1261 & $81.9 \%$ & \\
\hline \multirow[t]{2}{*}{ Q92 } & \multirow[t]{2}{*}{ GSE7958 } & 3/3 (3 mth) & \multirow[t]{2}{*}{ striatum } & \multirow[t]{2}{*}{ GPL1261 } & \multirow[t]{2}{*}{$81.9 \%$} & \\
\hline & & 3/3 (18 mth) & & & & \\
\hline $\mathrm{R} 6 / 2$ & GSE10263 & $9 / 9$ & striatum & GPL1261 & $81.9 \%$ & \\
\hline YAC128 & GSE19677 & 4/4 (12 mth) 3/6 (24 mth) & striatum & GPL1261 & $81.9 \%$ & [24] \\
\hline
\end{tabular}

The abbreviations for the datasets are as follows: main $\mathrm{HD}=$ main Huntington's disease dataset; $\mathrm{AD}=\mathrm{Alzheimer}$ 's disease; $\mathrm{ALS}=\mathrm{Amyotrophic} \mathrm{lateral} \mathrm{sclerosis;}$ HD-II = Huntington's disease dataset 2; MS = multiple sclerosis; PD = Parkinson's disease; SCHIZ = schizophrenia; DM1, DM2 = myotonic dystrophy type 1, type 2; $\mathrm{DMD}=$ Duchenne muscular dystrophy; $\mathrm{DCM}=$ dilated cardiomyopathy; $\mathrm{RCC}=$ renal cell carcinoma; $\mathrm{GG}=$ ganglioglioma; $\mathrm{Q} 80=H d h{ }^{80 \mathrm{Q}} ; \mathrm{Q} 150=H d h \mathrm{Q} 150 ;$ $\mathrm{Q} 92=H d h^{\mathrm{Q} 92}$. Accession is the accession number of the EMBL-EBI ArrayExpress, or NCBI Gene Expression Omnibus (GEO). Ctr/patient and WT/tg gives the sample numbers after outlier removal for control (ctr) or patient samples and wild type (WT) or HD mouse model samples (HD), respectively. For details of outlier removal procedure see materials and methods. Array lists the microarray type used for the particular study; for details see the GEO database. Overlap gives the percentage of genes, which are detected on the particular chip in comparison to the main HD array (GPL96).

mouse samples. To this end, we computed a network for the human control samples and calculated the preservation Z-summary score for its modules in the R6/2 wild type samples, or all mouse wild type data except the Q80 dataset, respectively (Figure $5 \mathrm{C}$ and $\mathrm{D}$ ). We only included genes that were conserved between both species. Both meta analyses of control human caudate nucleus and wild type mouse striatum data were very comparable and we obtained median Z-summary values of less than 5 for the preservation of modules of defined sizes (Figure $5 \mathrm{C}$ and $\mathrm{D}$ ). This led us to hypothesize that Z-summary values above this value would indicate high crossspecies preservation and would be correlated to effects induced by mutant huntingtin. The Q80 dataset was obtained with a different type of microarray than the other mouse datasets (Table 5), in which only about $50 \%$ of the genes were conserved and therefore Z-summary values were very low (Figure 5E). In general, for the other mouse datasets, preservation was better in fully symptomatic animals (Figure 5E, compare time points for Q92 and YAC128), with absolute age of the animals being irrelevant. Given our data for the control/wild type cross-species comparison (Figure 5C and D), the negatively correlated modules of the human HD caudate nucleus dataset were very highly preserved in the mouse models, while the positively correlated modules were in general less highly preserved (Figure 5E).

To reveal further similarities between gene expression in the human HD samples and other disorders or the mouse models, respectively, we computed consensus networks. In this type of network, only genes, which are similarly regulated in both disorders or species and which are assigned to modules that are correlated with the trait of interest in both datasets, are analyzed. In our preservation analysis we observed very high Z-summary values for the PD dataset (Figure 5A). Accordingly, we also identified consensus modules, which were highly correlated both with $\mathrm{HD}$ and PD disease states (Figure 6A and B). Gene 


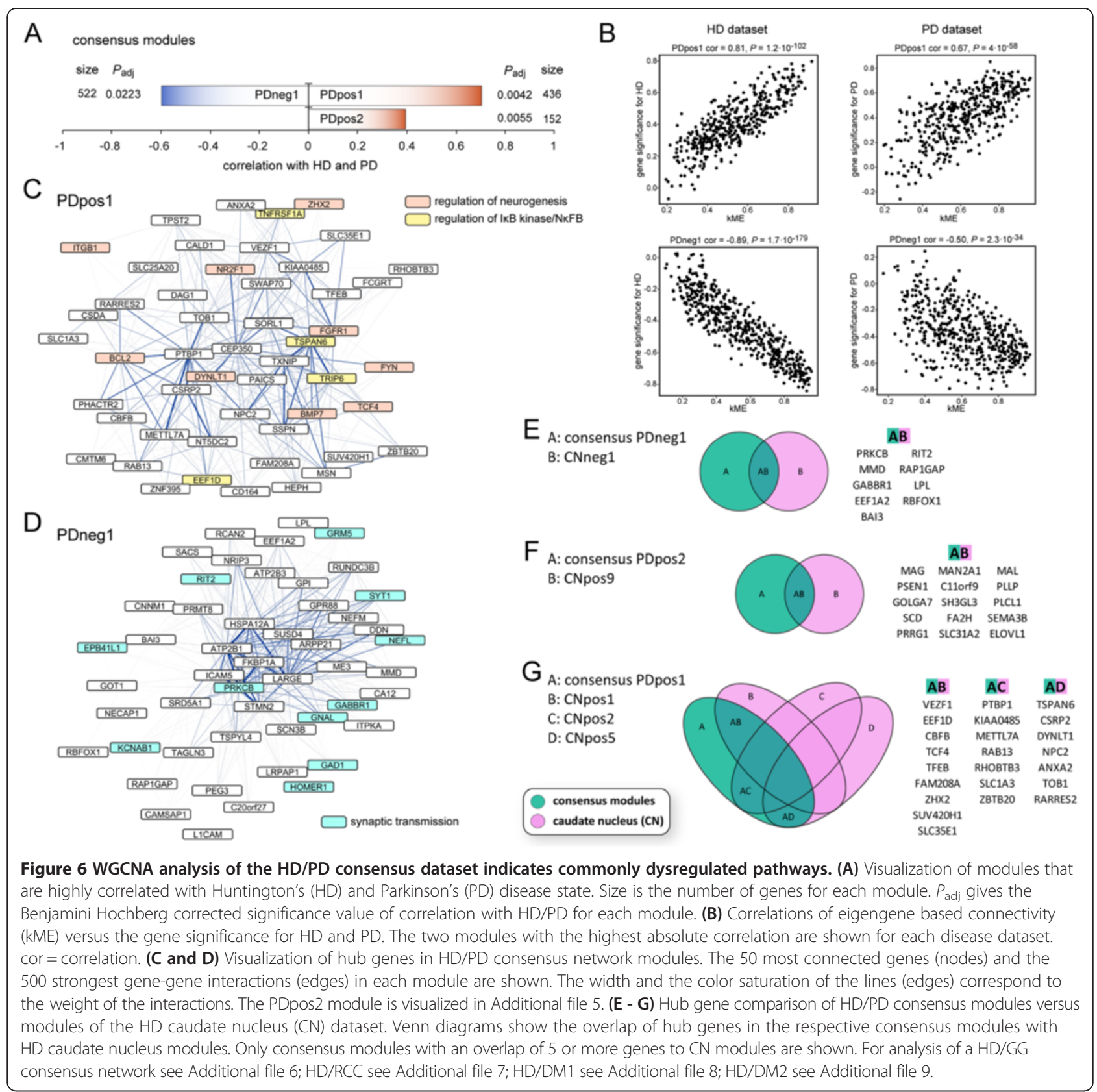

ontology enrichment and hub gene analysis showed that these modules, which were positively correlated with HD and $\mathrm{PD}$, were enriched in genes implicated in NFKB signaling, neurogenesis and lipid synthesis (Figure 6C, Table 6 and Additional file 5). The negatively correlated module in the HD/PD consensus network was enriched for genes involved in synaptic and mitochondrial function, as well as calmodulin binding proteins (Figure 6D and Table 6). In addition, there was a high overlap of hub genes of consensus network modules with the hub genes that we identified in the caudate nucleus dataset (Figure 6E-G). Interestingly, several Alzheimer's disease related genes
(PSEN1, SORL1, FGFR1, BMP7, FYN, BCL2, SCD, NPC2, PTBP1, TNFRSF1A, ITGB1, LHPP, LRP2, LRPAP1, LPL, L1CAM, CNNM1 and HSPA12A) had hub gene status in this HD/PD consensus network (Figure 6E-G). Next, we analyzed consensus networks of the HD caudate nucleus dataset with the datasets of other disorders, the same we had used in the preservation analysis. We did not find significantly correlated modules (with disease) in the consensus networks for HD with AD, ALS, MS and SCHIZ. However, we could identify significantly correlated modules with the two cancer datasets (Additional files 6 and 7) and the two types of myotonic dystrophies 
Table 6 Gene ontology enrichment for the consensus networks in human datasets

\begin{tabular}{|c|c|c|c|}
\hline Module & cor & GO-term (DAVID) & Potential regulators \\
\hline \multicolumn{4}{|c|}{ Parkinson's disease (PD) } \\
\hline PDpos1 & up & IkB kinase/NFkB $(3.59,0.032)$ & \\
\hline PDpos2 & up & lipid synthesis $(2,0.01)$ & \\
\hline \multirow[t]{3}{*}{ PDneg1 } & down & synapse $(5.87,0.000)$ & $\operatorname{miR} 16(0.036)^{1}$ \\
\hline & & mitochondrion $(4.6,0.000)$ & ESRRA $(0.001)^{2}$, SF1 $(0.003)^{2}$ \\
\hline & & calmodulin binding $(3.12,0.044)$ & \\
\hline \multicolumn{4}{|c|}{ Myotonic dystrophy type 1 (DM1) } \\
\hline DM1pos1 & up & regulation of neurogenesis $(1.55,0.99)$ & $\begin{array}{l}\text { MEF2 }(0.040)^{2}, \text { E2F }(0.040)^{2}, \operatorname{NR3C1}(0.040)^{2}, \\
\text { PITX2 }(0.040)^{2}, \text { ATF6 }(0.040)^{2}, \operatorname{VDR}(0.040)^{2}, \text { ATF1 }(0.040)^{2}, \\
\text { TP53 }(0.041)^{2}\end{array}$ \\
\hline DM1neg1 & down & axon $(1.18,0.98)$ & POU2F1 $(0.011)^{2}$, POU1F1 $(0.034)^{2}$, IRF2 $(0.048)^{2}$ \\
\hline DM1neg2 & down & enzyme activator activity $(2.52,0.049)$ & \\
\hline DM1neg3 & down & synapse $(2.29,0.008)$ & SF1 $(0.001)^{2}$, REST $(0.032)^{2}$ \\
\hline \multicolumn{4}{|c|}{ Myotonic dystrophy type 2 (DM2) } \\
\hline DM2pos1 & up & lysosome $(3.03,0.043)$ & \\
\hline DM2pos2 & up & regulation of transcription $(1.51,0.99)$ & \\
\hline DM2pos3 & up & tubulin binding $(1.64,0.52)$ & \\
\hline DM2pos4 & up & sarcomer $(1,1.0)$ & \\
\hline DM2neg1 & down & mitochondrion $(3.09,0.01)$ & \\
\hline DM2neg2 & down & dendrite $(1.91,0.51)$ & $\operatorname{NRF1}(0.009)^{1}$, ETS1 $(0.054)^{1}$ \\
\hline \multicolumn{4}{|c|}{ Ganglioglioma (GG) } \\
\hline \multirow[t]{2}{*}{ GGpos1 } & up & inflammatory response $(6.32,0.002)$ & NFKB $(0.022)^{1}$, miR124 $(0.022)^{1}$, miR106b $(0.022)^{1}$, MYOG $(0.066)^{1}$ \\
\hline & & cell adhesion/extracellular matrix $(4.13,0.002)$ & $\begin{array}{l}\text { ELF1 }(0.000)^{2}, \text { IRF8 }(0.008)^{2}, \text { MYB }(0.008)^{2}, \text { ELK1 }(0.010)^{2}, \\
\text { SPI1 }(0.010)^{2}, \text { CEBPA }(0.016)^{2}, \text { NFAT }(0.029)^{2}, \text { IRF1 }(0.034)^{2}, \\
\text { STAT5A }(0.034)^{2}, \text { AHR }(0.043)^{2}, \text { SOX5 }(0.049)^{2}, \text { TP53 }(0.049)^{2}\end{array}$ \\
\hline \multirow[t]{7}{*}{ GGneg1 } & down & axon $(11.88,0.000)$ & \multirow{7}{*}{$\begin{array}{l}\text { REST }(0.000)^{2}, \text { SF1 }(0.000)^{2}, \text { TCF3 }(0.000)^{2}, \text { ESRRA }(0.000)^{2}, \\
\text { MYOD }(0.000)^{2}, \text { RFX1 }(0.000)^{2}, \text { RORA }(0.000)^{2}, \text { EGR }(0.000)^{2}, \\
\text { JUN }(0.000)^{2}, \text { TCF11 }(0.000)^{2}, \text { ATF3 }(0.000)^{2}, \text { LEF1 }(0.000)^{2}, \\
\text { PAX4 }(0.000)^{2}, \text { E4F1 }(0.000)^{2}, \text { CREB }(0.000)^{2}, \text { HLF }(0.001)^{2}, \\
\text { MAZ }(0.001)^{2}, \text { SP1 }(0.001)^{2}, \text { NFIL3 }(0.001)^{2}, \text { BACH1 }(0.002)^{2}, \\
\text { ATF2 }(0.002)^{2}, \text { ATF1 }(0.002)^{2}, \text { TFAP4 }(0.002)^{2}, \text { TCF8 }(0.003)^{2}, \\
\text { ZNF238 }(0.004)^{2}, \text { NFE2 }(0.005)^{2}, \text { HSF1 }(0.006)^{2}, \text { MIF }(0.010)^{2}, \\
\text { CUTL1 }(0.012)^{2}, \text { SREBF1 }(0.016)^{2}, \text { NF1 }(0.020)^{2}, \text { MEIS1 }(0.020)^{2} \text {, } \\
\text { HSF2 }(0.021)^{2}, \text { NFE2L2 }(0.021)^{2}, \text { PCAF }(0.023)^{2}, \text { GCF1 }(0.034)^{2}, \\
\text { ITGAL }(0.034)^{2}, \text { ATF4 }(0.035)^{2}, \text { MAF }(0.038)^{2}, \text { TAL1 }(0.043)^{2}, \\
\text { NR1H4 }(0.044)^{2}, \text { GATA2 }(0.044)^{2}, \text { SOX9 }(0.046)^{2}\end{array}$} \\
\hline & & synapse $(11.64,0.000)$ & \\
\hline & & microtubuli based transport $(5.18,0.000)$ & \\
\hline & & calmodulin binding $(4.87,0.000)$ & \\
\hline & & cytoskeleton $(3.63,0.000)$ & \\
\hline & & neuropeptide $(1.96,0.012)$ & \\
\hline & & signaling from G-protein families $(1.49,0.025)$ & \\
\hline \multicolumn{4}{|c|}{ Renal cell carcinoma (RCC) } \\
\hline \multirow[t]{8}{*}{ RCCpos1 } & up & inflammatory response $(12.47,0.000)$ & $\operatorname{NFKB}(0.06)^{1}, \mathbf{E} 2 F(0.081)^{1}$ \\
\hline & & regulation of IkB kinase/NFkB $(5.54,0.000)$ & \multirow{7}{*}{$\begin{array}{l}\text { IRF8 }(0.000)^{2}, \text { IRF1 }(0.000)^{2}, \text { ETS2 }(0.000)^{2}, \text { ELF1 }(0.000)^{2}, \\
\text { SPI1 }(0.000)^{2}, \text { ELF2 }(0.001)^{2}, \text { STAT1 }(0.001)^{2}, \text { E2F }(0.001)^{2}, \\
\text { ETS1 }(0.007)^{2}, \text { GABPA }(0.007)^{2}, \text { ELK1 }(0.010)^{2}, \text { STAT5B }(0.021)^{2}, \\
\text { FOXO4 }(0.022)^{2}, \text { TP53 }(0.024)^{2}, \text { AHR }(0.025)^{2} \text {, ETV4 }(0.026)^{2}, \\
\text { STAT3 }(0.032)^{2}, \text { SMAD1 }(0.037)^{2}, \text { IRF7 }(0.037)^{2}, \text { AR }(0.040)^{2}\end{array}$} \\
\hline & & angiogenesis $(5.17,0.004)$ & \\
\hline & & caspase recruitment $(4.8,0.002)$ & \\
\hline & & regulation of transcription $(4.03,0.003)$ & \\
\hline & & regulation of apoptosis $(3.09,0.004)$ & \\
\hline & & extracellular matrix $(2.81,0.005)$ & \\
\hline & & chromatin $(2.6,0.023)$ & \\
\hline RCCpos2 & up & semaphorin/CD100 antigen $(1.45,0.023)$ & \\
\hline
\end{tabular}


Table 6 Gene ontology enrichment for the consensus networks in human datasets (Continued)

\begin{tabular}{|c|c|c|c|}
\hline \multirow[t]{3}{*}{$\overline{\text { RCCneg1 }}$} & \multirow[t]{3}{*}{ down } & mitochondrion $(31.99,0.000)$ & CREB $(0.006)^{1}, \operatorname{NRF} 1(0.006)^{1}$, miR16 $(0.068)^{1}$ \\
\hline & & protein catabolic process/proteasome $(2.29,0.037)$ & \multirow{2}{*}{$\begin{array}{l}\text { SF1 }(0.000)^{2}, \text { ESRRA }(0.000)^{2}, \text { E4F1 }(0.006)^{2}, J U N(0.030)^{2}, \\
\text { ATF3 }(0.030)^{2}, \text { NRF1 }(0.047)^{2}\end{array}$} \\
\hline & & synaptic vesicle $(1.34,0.029)$ & \\
\hline
\end{tabular}

(Additional file 8 and 9). Taken together, in these consensus networks, the negatively correlated modules were mostly enriched for genes involved in neuronal and mitochondrial function, the positively correlated modules were mostly enriched for inflammatory pathway genes in the two cancers and for regulators of transcription and neurogenesis in DM1 and DM2 (Additional files 6, 7, 8 and 9 and Table 6). This largely mirrored the preservation analysis (Figure 5). We also could identify significantly correlated modules in the R6/2 and HdhQ150 datasets (Figures 7 and 8). The negatively correlated modules for both mouse models were enriched for synaptic genes (Figures 7C and D, 8D and Table 7) and many of these also had hub genes status in the human CNneg1 module (Figures 7F and $8 \mathrm{E}$ ). $\mathrm{GO}$ analysis of the positively correlated module in the human HD/R6/2 consensus network showed genes involved in lipid metabolism and regulation of neurogenesis (Figure 7E and Table 7). In the positively correlated module of the human $\mathrm{HD} / \mathrm{HdhQ} 150$ consensus network, we found an enrichment for extracellular matrix genes and regulators of cell development (Figure $8 \mathrm{C}$ and Table 7). Furthermore, the positively correlated modules for both mouse models exhibited extensive overlap of hub genes with positively correlated modules in the human caudate nucleus dataset (Figures $7 \mathrm{G}$ and $8 \mathrm{~F}$ ).

\section{Discussion}

In this study we use weighted correlation networks to analyze gene expression data from different brain regions of HD patients and compared them to other disorders and HD mouse models. In summary, we found comparable dysregulation to previously reported changes [27] in the BA4 and BA9 regions of the frontal cortex and the caudate nucleus. However, in contrast to previous findings, our analysis of the cerebellum detected extensive transcriptional dysregulation, to a similar extent to that seen in the BA4 region of the frontal cortex. Subsequent in depth comparison of the brain region specific networks revealed an underlying common transcriptional signature in all three brain regions: a negative correlation with HD for mitochondrial function, glycolysis, intracellular protein transport, proteasome and synaptic vesicles and a positive correlation with HD for metallothioneins and genes involved in stress response pathways and angiogenesis. Moreover, meta analyses of the caudate nucleus network and other disorders showed similarities for these disorders with HD, in particular with a high enrichment for inflammatory pathway genes. Lastly, we compared well studied HD mouse models to the human gene expression dataset, which implied that whilst the mouse models mimic some aspects of the disease very well, certain aspects, for example induction of the inflammatory response, were only poorly reflected.

Yet, there are certain limitations and considerations for data interpretation of the current study. As with all post mortem tissues, RNA quality might be a problem. However, the authors of the original publication used rigorous standards to ensure comparable RNA quality and microarray reads [27]. In addition, we used a connectivity based outlier test to remove samples that didn't pass our quality control [38] (see also materials and methods section). A further consideration is that the post mortem samples provide a snapshot of end stage disease gene expression, which might not necessarily reflect the underlying changes at or before disease onset or during disease progression. We consequently found the best preservation of human striatal gene expression changes in late stage mouse models (Figure 5E). Collection of patient samples, e.g. from peripheral tissues such as muscle at different disease stages might shed more light on the regulation of gene expression during disease progression. What's more, the massive amount of neurodegeneration, greater than $90 \%$ in the striatum for grade 4 brains [39], poses the danger that changes in tissue/cell type composition are compared rather than changes in gene expression. Hodges and colleagues addressed this issue with laser-capture micro-dissection of control and patient tissue (grade 1) followed by the analysis of the same number of neurons for both. They found similar trends for gene expression changes in the captured neurons as compared to the tissue-based analysis and therefore, concluded that these changes occurred before cell death [27]. Our preservation and consensus network analyses showed that the mouse models very well mirror the "synaptic/neuronal" CNneg1 module of the human caudate nucleus network and in fact we observed the highest preservation scores for this module (Figure 5E). Furthermore, we found high enrichment 


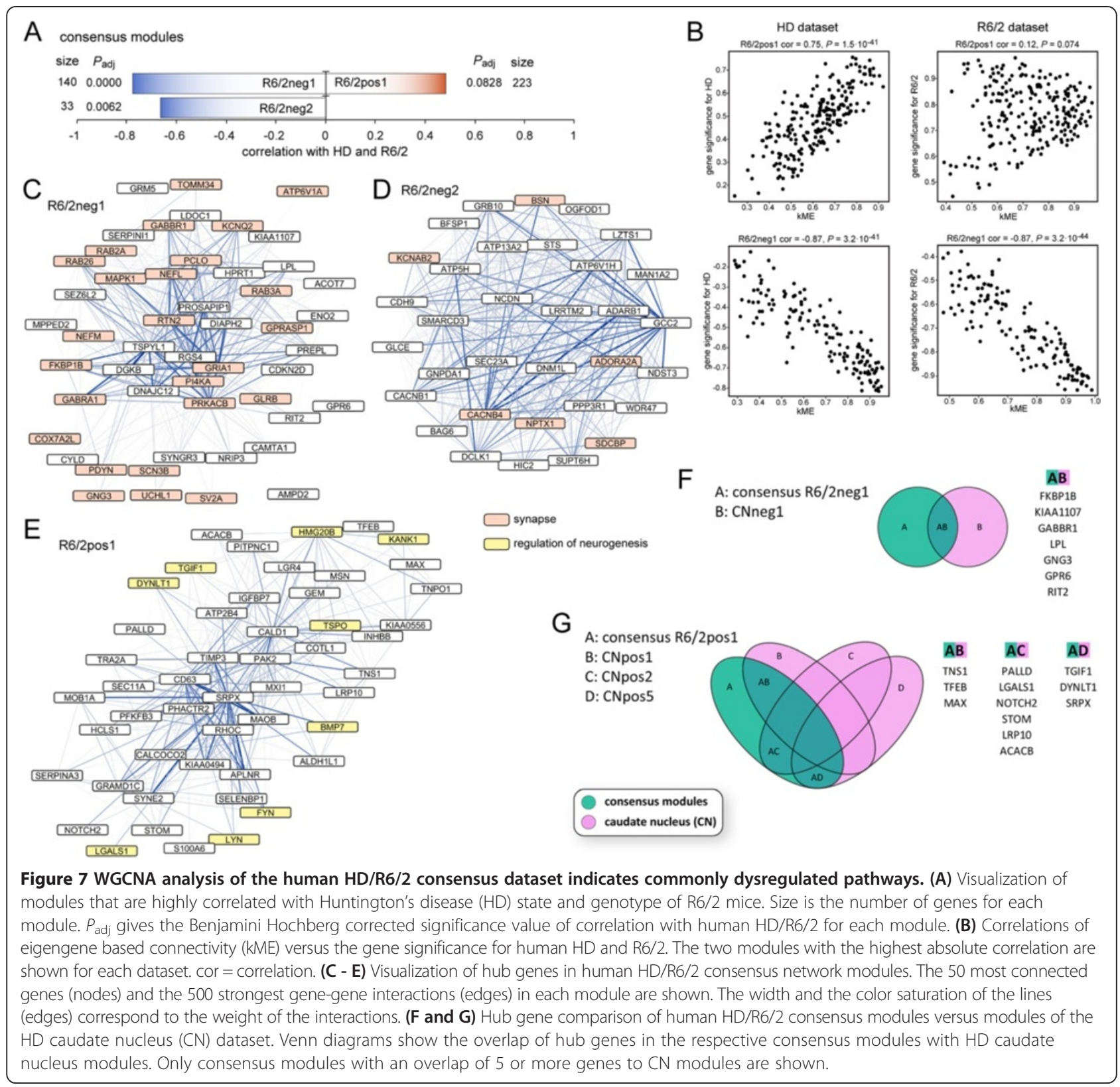

for synaptic and neuronal genes in the negatively correlated modules in the R6/2 and HdhQ150 consensus networks (Figures 7, 8 and Table 7). Given that very little striatal neurodegeneration occurs in both mouse models [40-42], the observed gene expression changes in the human datasets are most probably not due to differences in tissue composition and could therefore, at least partly, be the underlying cause for neuronal cell death. As for all bioinformatic predictions of dysregulated pathways in vivo validation is the logical next step. Regrettably, we do not have access to human HD brain tissue in sufficient quantity and quality to test the predictions of our analysis. For many, although not all of the predicted dysregulated pathways, there is an extensive literature that provides evidence for attenuated function in HD mouse models and HD patients (reviewed for example in $[43,44]$ ). Given that many of our predicted dysregulated pathways have been corroborated through the research reported by others, we expect that some of the novel predicted pathways will be confirmed in future studies as being affected in HD.

In a previous publication, Horvath and colleagues used a network based approach to compare the same HD patient caudate nucleus gene expression dataset to the modular structure of the transcriptome in normal human brains [30,38]. The focus of the study was however on the biologically meaningful relationship between samples, which can be distinguished with a connectivity based analysis. Nevertheless, they identified a module 


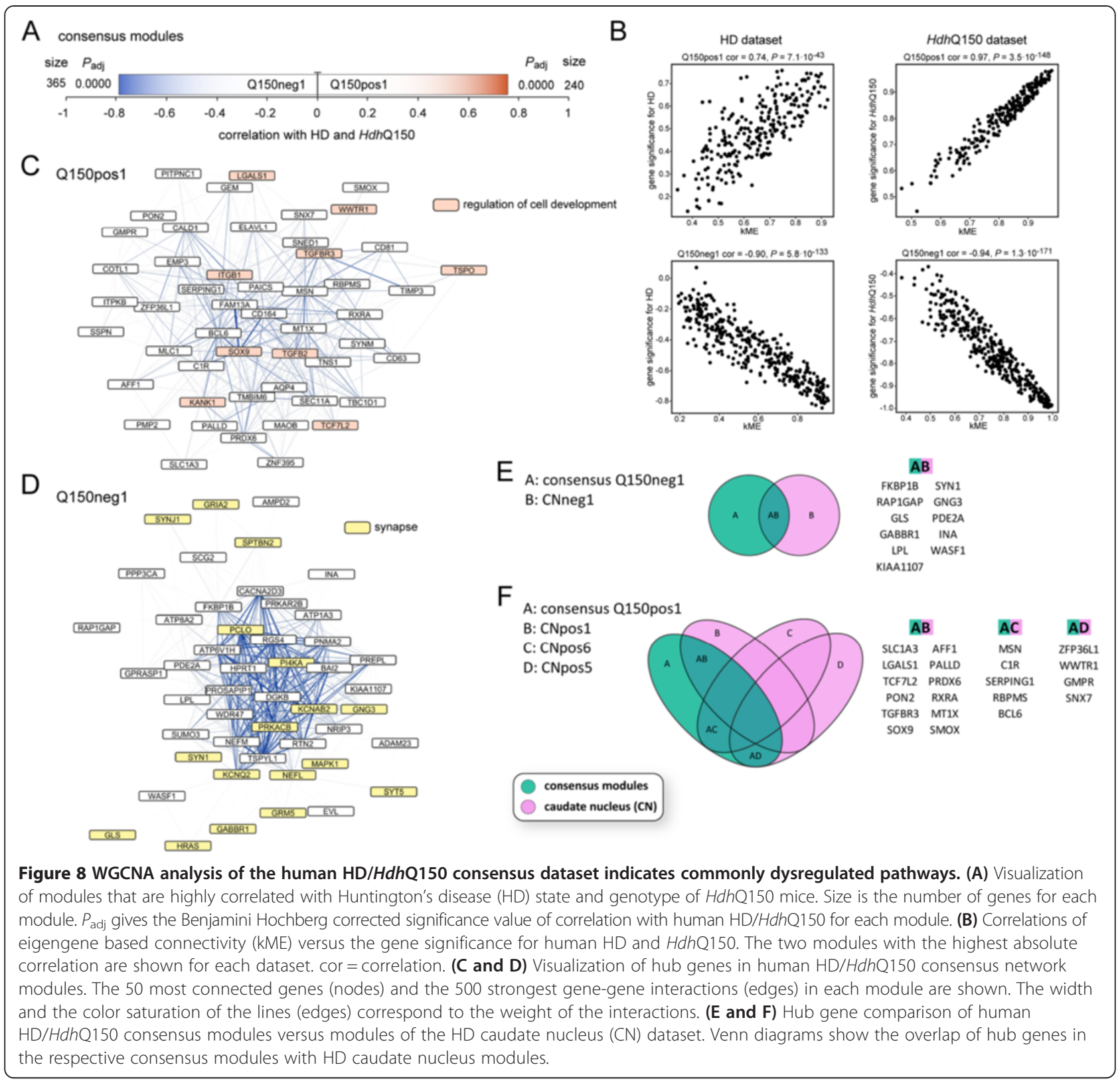

that had considerable similarity with the salmon "neuronal, synaptic and signal transduction" module of the normal human transcriptome and which was altered in HD. This is in very good agreement with our data, where we identified a homologous module (CNneg1) in the caudate nucleus network.

It is noteworthy to mention that a linear relationship between the correlation of a gene with disease and differential expression analysis does not necessarily exist. Therefore, although a gene can be highly correlated with a particular trait, the change in expression level can be relatively small. With standard dysregulation analysis, gene expression changes in a subpopulation of cells might be lost in a background of non-affected cells. With network analysis, we were able to find highly comparable GO enrichments and hub gene structures for the frontal cortex BA4 region even when analyzed together with the unaffected BA9 region. This implies that a weighted gene network approach can detect gene expression changes in a sub-population of cells, even against a huge background of expression signals of the same genes in unaffected tissue. The only major difference in analysis of the combined tissues was a reduction in the correlation of the modules with HD (Figures $1 C$ and D, Table 3 and Additional files 10 and 11). We observed relatively small, yet statistically significant correlations of modules in the cerebellum with HD when compared to caudate nucleus, a finding, which is similar to that found in an HD mouse model 


$\begin{aligned} & \text { Table } 7 \text { Gene ontology enrichment for the consensus } \\
& \text { networks in mouse datasets }\end{aligned}$
\begin{tabular}{llll}
\hline Module cor & GO-term (DAVID) & $\begin{array}{l}\text { Transcription } \\
\text { factor }\end{array}$ \\
\hline HdhQ150 & & & \\
Q150pos1 & up & extracellular matrix $(1.71,0.65)$ & \\
Q150neg1 down & $\begin{array}{l}\text { synaptic transmission/synapse } \\
(8.81,0.000)\end{array}$ & CREB $(0.045)^{1}$ \\
& & $\begin{array}{l}\text { neuron projection/axon } \\
(2.4,0.019)\end{array}$ & \\
& & mitochondrion $(2.1,0.007)$
\end{tabular}

\section{$\mathrm{R} 6 / 2$}

$\begin{array}{llll}\text { R6/2pos1 } & \text { up } & \text { fatty acid metabolism } & \text { SOX9 }(0.049)^{2} \\ & & (1.98,0.13) \\ \text { R6/2neg1 down } & \text { synaptic transmission } \\ & (6.77,0.000) \\ & & \text { gated channel activity } \\ & (2.3,0.02) \\ & & \text { neurotransmitter transport } \\ & & (2.08,0.005) \\ & & \text { ion transport }(1.68,0.64)\end{array}$

Gene ontology (GO) enrichment for the consensus network analysis of the HD caudate nucleus dataset with HD mouse models. Genes in the identified modules were analyzed using DAVID. The sign of the correlation (cor) and the over-represented GO-terms are shown. The first number in brackets after the GO-term is the respective fold enrichment, the second number the adjusted $P$-value, as determined by DAVID. All significantly enriched (adjusted $P<0.05$ ) GO-terms are shown. In cases where no significantly enriched GO-term was identified, the GO-term with the highest fold enrichment is shown. Potential regulators of a module were identified using ${ }^{1} \mathrm{GO}$-Elite, or ${ }^{2} \mathrm{WebGestalt}$. Adjusted $P$-values are given in brackets after the name.

[45]. One explanation for this effect could be that only a sub-population of cells in the cerebellum, yet to be determined, is affected.

In all three brain regions, we found genes involved in the function of mitochondria, glycolysis, intracellular protein transport, proteasome and synaptic vesicles to be commonly negatively correlated with $\mathrm{HD}$, and metallothioneins and genes involved in stress response pathways and angiogenesis to be commonly positively correlated with HD (Table 4). This led us to hypothesize that the HD mutation causes a common transcriptional signature (Figure 5). Furthermore, the preservation of modules between each of the three brain region networks was generally very high, with only a few tissue specific modules (Figure 2). The CNpos5 module, specific to the caudate nucleus network, is potentially very interesting by virtue of its large size and correlation with $\mathrm{HD}$ (Figure $2 \mathrm{E}$ and $\mathrm{F}$ ) and provides a good example of the drawbacks of gene ontology enrichment analysis. Historically driven, the gene ontology databases do not include the central nervous system specific functions of genes and are, as all large databases, plagued with incompletion, imprecision and a bias towards certain, well studied pathways [46]. So the only enriched functional cluster for this module contained genes implicated in cilium function (Table 3). Also, most probably because of the same aforementioned reasons, an upstream regulator was not identified. Yet, one of the advantages of connectivity based network analysis is the ranking of genes according to their co-regulation with other genes. This allows one to identify hub genes, which often are the biological key players in a particular module [47]. And indeed, 7 of the top 50 hub genes of the CNpos5 module have a probable function in extracellular matrix organization (CSGALNACT1, CYR61, ANXA2, AGT, COL21A1, EFEMP1 and ECM2).

In addition to the newly identified transcriptional signature in the cerebellum, we found highly positively correlated modules enriched for genes involved in inflammation for both the cortex BA4 region and caudate nucleus (Tables 2 and 3). This is probably not surprising given the widespread gliosis that occurs in the brains of HD patients [48], however it was not identified in the original analysis [27]. A gene expression network study in late-onset $\mathrm{AD}$ identified an immune system/microglia module that was highly correlated with AD pathology [49]. In our comparison of HD with other disorders, the two "inflammatory" modules CNpos6 and CNpos8 were largely preserved in most disorders (Figure 5A) raising the possibility that treatments available for some of these could also be applied to HD [50-52]. Recently, mutant HTT was found to induce a cell-autonomous response in microglia [53] and astrocytes [54], which are first indications that neuroinflammation in HD is a potential contributing factor and not purely the consequence of neurodegeneration. Especially in the caudate nucleus network, we identified components of the complement system as being positively correlated with HD and many of these also had hub gene status (Additional file 4E and G). It has been previously reported that the complement system is abnormally activated in the brains of HD patients [55]. The complement system is regulated by the innate, as well as the adaptive immune system and is expressed in most cell types of the brain, thus it might be an important factor in neurodegenerative diseases [56]. Taken together, our data and previous findings suggest that targeting neuroinflammation, in particular activation of the complement system could be beneficial to slow down disease progression in HD.

Whether the abnormal folding of mutant HTT and/or the appearance of aggregates are sufficient to induce a cellular stress response, in particular through induction of steady state levels of molecular chaperones, is a longstanding question. To the best of our knowledge, our network analysis is the first indication that the expression of mutant HTT is correlated with higher levels of molecular chaperones in humans. We identified a significantly positively correlated module in the cerebellum network (CBpos5, Figures 1B and 3A, Table 1), which is 
highly enriched for protein folding/chaperone genes. We also found a similar module in the cortex BA4 network, that was just short of being significantly correlated (FC4pos4, Figure 1D, Table 2 and Additional file 3C). In contrast, we did not detect a similar module in the caudate nucleus network. It is tempting to speculate that the higher levels of these chaperones counteract the pathogenic effects of mutant HTT and protect these tissues (correlation $P$-value of chaperone modules $\mathrm{CB}<\mathrm{FC}$ $\mathrm{BA} 4<\mathrm{CN}$; pathogenesis $\mathrm{CB}<\mathrm{FC}-\mathrm{BA} 4<\mathrm{CN}$ ). We of course appreciate that further studies are needed, e.g. to investigate whether changes at the mRNA level are translated to changes at the protein level by assessing the protein levels of certain chaperones in different brain regions. In the frontal cortex BA4 region network we also identified a chaperone gene containing module that was negatively correlated with HD (FC4neg5, Table 2) highlighting the complex regulation of the proteostasis network and its potential suppression through other mechanism caused by mutant HTT. Together these data support the therapeutical avenue of drugs that boost the proteostasis network, which was shown numerous times in animal models to antagonize the progression of HD pathogenesis [57]. Given that the proteostasis networks in mammals does not seem to be impaired during aging [58], this approach might prove beneficial even in older patients.

As briefly addressed in the introduction, aberrant binding of an mRNA processing factor to the mutant HTT transcript results in the production of a HTT exon 1 fragment [19]. It might be expected that such an RNA toxicity based mechanism would have additional widespread consequences on global alternative splicing, similar to sequestration of MBNL1 in myotonic dystrophy. In fact, an unpublished study has identified various alternatively spliced transcripts in HD mouse model tissue (Gipson TA and Housman DE, unpublished data) and an increase of the $4 R / 3 R$ tau mRNA ratio has been observed [59]. Intriguingly, we identified at least one module that was significantly enriched for genes involved in RNA binding/mRNA processing in all three brain region networks (Tables 1, 2 and 3), which had not been discovered in the original publication. In all cases the modules were positively correlated with HD indicative of an upregulation of some parts of the RNA processing machinery. It will be very interesting to see in future studies, which splicing factors are mis-regulated and the consequences this has on general RNA processing in HD.

The similarities between HD and other neurodegenerative diseases point towards common pathogenic mechanisms (Figures 5, 6 and Additional files 6, 7, 8 and 9). Apart from the previously mentioned inflammatory component, we observed very high preservation scores for the CNneg2 module of the caudate nucleus network
(Figure 5A). This module likely represents the commonly down-regulated genes in $\mathrm{HD}$, rather that changes in tissue composition due to a loss of neurons (see Results section). GO enrichment analysis showed that processes like mitochondrial function, the proteasome, stress response, etc. are probably affected (Table 3 ). There is extensive literature in PD about mitochondrial dysfunction and the involvement of parkin and PINK1 in quality control and maintenance of mitochondria [60]. Interestingly, PINK1 is a hub gene in the frontal cortex BA4 module that was enriched for genes involved in mitochondrial function (FC4neg5, Figure 1F and Table 2). As already mentioned in the results section, several genes altered in Alzheimer's disease are hub genes in the HD/PD consensus network (Figure 6). Collectively these data suggest that some key proteins could underpin the functional deficits observed in various disorders.

The in depth analysis of the hub genes in the different networks, in particular the common ones in all three brain regions uncovered previously identified therapeutic targets (Figure 5). In model systems of HD, for example subcutaneous administration of FGF2 increased neurogenesis [61] and overexpression of metallothioneins conferred neuroprotection against polyglutamine induced excitotoxicity [62]. Furthermore, predicted upstream regulators of the identified network modules e.g. HSF1 [63], NFAT [64], XBP1 [65], ELK1 [66], JUN [67], REST [68], or CREB1 [69] were all shown to modulate neurotoxicity in HD. This clearly shows the power of weighted correlation network analysis for the prediction of therapeutic targets. Therefore, modulation of transcription factors, not yet implicated in HD, like certain members of the STAT transcription factor family (immune response), TCF3 (immune response), TCF12 (lineage-specific gene expression, initiation of neuronal differentiation), EGR1 (differentiation, mitogenesis), EGR2/4 (immune response), IRF1 (immune response, apoptosis), GABPB1 (mitochondrial function), or PAX4 (development, tumorigenesis) could lead to new strategies towards slowing down pathogenesis in Huntington's disease.

\section{Conclusions}

Using weighted gene correlation network analysis we demonstrate that the Huntington's disease mutation causes a common signature of gene expression changes in patient brain tissue. We have identified as yet unknown extensive transcriptional dysregulation in the cerebellum of HD patients, similar to that which we have observed in the frontal cortex and caudate nucleus. Additionally, we found that yet unassociated pathways, e.g. global mRNA processing, were dysregulated in HD. Meta analyses of the HD networks and other disorders showed similarities for these disorders with HD, in particular with a high enrichment for inflammatory pathway genes. Lastly, we compared well 
studied HD mouse models to the human gene expression dataset, which implied that whilst the mouse models mimic some aspects of the disease very well, certain aspects, for example induction of the inflammatory response, were only poorly reflected. Taken together, these approaches allowed us to gain novel insights into the molecular pathogenesis of $\mathrm{HD}$ and to pinpoint potential future therapeutic targets.

\section{Methods}

\section{Microarray datasets and data pre-processing}

All datasets were obtained from the EMBL-EBI ArrayExpress [70], or NCBI Gene Expression Omnibus (GEO) [71] websites. Accession numbers for the datasets and experimental details can be found in Table 5. Microarray raw intensity files were MAS5 normalized (Affymetrix Expression Console, Affymetrix, CA, USA) [72] and log2 transformed to obtain the raw data datasets. We used only the HG-U133A data for the main HD dataset [27]. For the neurodegenerative diseases dataset [35], the array files were normalized using the Rosetta error model (Rosetta Biosoftware, WA, USA) and $\log 2$ transformed to obtain the raw data dataset. All raw datasets were collapsed to a one probe per gene level using the $\mathrm{R}$ function collapseRows [73]. Microarray probes were matched to gene names and Entrez gene IDs (NCBI) of homo sapiens genome build hg19 (Consensus CDS, NCBI), if the annotation was not provided by the affymetrix array annotation file (Affymetrix Expression Console, Affymetrix, CA, USA). Probes with ambiguous gene annotations were removed. Outlier samples were removed by a completely unbiased method, which ignores phenotypic traits. To this end the Euclidian distance between samples in a network and their connectivity was calculated. Subsequently, samples with a standardized connectivity of less than -2.5 were removed.

\section{Weighted gene co-expression network analysis (WGCNA)}

All networks were independently constructed from the $\log 2$ transformed, pre-processed datasets. In principle, the workflow of the original publications was used [29]. Briefly, the pair wise weighted Pearson correlations between all pairs of genes across all samples were calculated. A signed adjacency matrix was calculated by raising the co-expression matrix to a soft-threshold power to reach approximate scale free topology of the network $\left(R^{2}>0.9\right)$. The powers used were: 15 for cerebellum, 9 for caudate nucleus, 13 for frontal cortex (BA4), 17 for frontal cortex (BA9) and 13 for frontal cortex (BA4 and BA9 combined). A signed topology overlay matrix was calculated based on the transformed connection strengths, which gives a biologically meaningful measurement of the similarity of the co-expression of two genes with all other genes in the network. Highly similarly expressed genes were grouped by applying average linkage hierarchical clustering on the topology overlay matrix. Modules were subsequently identified by the dynamic hybrid tree cut algorithm [74]. Module eigengenes can be seen as representing the first principal component of a module. Modules with highly correlated module eigengenes were merged $(r>0.8)$. To identify biological meaningful modules, we correlated the module eigengenes to the HD stage assignment of the samples [27]. Raw $P$-values were adjusted for multiple comparisons with the Benjamini and Hochberg correction using the Bioconductor package multtest [75].

\section{Consensus network construction}

Consensus networks were essentially constructed with the same methodology as described above for weighted gene co-expression network analysis. Briefly, outlier samples were removed from the collapsed raw datasets. Networks were constructed only from genes that were detected by both array types, if applicable. Powers for transformation of the co-expression matrices were (see Table 5 for abbreviations): 10 for $\mathrm{AD}, 19$ for ALS, 28 for DM1, 8 for DM2, 23 for GG, 12 for MS, 16 for PD, 15 for RCC, 9 for SCHIZ, 32 for YAC128, 20 for R6/2 and 20 for HdhQ150. Modules with highly correlated module eigengenes were merged $(r>0.6)$. Module eigengenes were subsequently matched to external traits as described before and corrected for multiple hypotheses testing.

\section{Module preservation statistics}

The WGCNA package includes statistical tests to analyze module preservation across different datasets [76]. Preservation is the similarity of interconnections between genes in a module, but also connectivity patterns of individual modules for the two data sets, i.e. high preservation is evidence for densely connected, distinct, and reproducible modules. We calculated 200 permutations of the preservation statistics and generated a Z-summary value by averaging them. The Z-summary indicates if a module is strongly preserved (Z-summary score $>10$ ), moderately preserved (Z-summary score $2<x<10$ ), or not preserved (Z-summary score $<2$ ).

\section{Identification and visualization of hub genes}

We used the eigengene based connectivity kME as a measure of module membership. Genes with a high module membership measure are referred to as intramodular hub genes. These genes are representative for the entire module and most likely are biological key players in the respective module. To visualize module structures, we extracted the 50 genes with the highest module membership (nodes) and the strongest 500 gene-gene connections (edges) amongst these from the signed topology overlay matrix. We used Cytoscape [77] to visualize the networks 
with the strength of the gene-gene correlation as a cofactor.

Enrichment of upstream regulators and pathway analysis To analyze enrichment of upstream regulators, like e.g. transcription factors or micro RNAs, we used GO-Elite [78], or WebGestalt [79]. For both, we used the gene lists for the identified network modules as input and all genes in a network as the denominator for the analysis with GO-Elite. The EnsMart65Plus database for homo sapiens was used in the GO-Elite analyses.

\section{Gene ontology analysis}

Gene ontology analysis was carried out with the Database for Annotation, Visualization and Integrated Discovery (DAVID) Bioinformatics Resource [80]. A list of all genes in the network analysis was used as a custom background for the gene ontology enrichment analysis. We summarized all gene ontology terms (GO-term) of similar subterms into an overarching term. Fold enrichment and Benjamini-Hochberg corrected $P$-values are shown for the respective GO-term cluster.

\section{Availability of data files}

The raw datafiles used in this study [24,27,28,35,81-85] were obtained from the EMBL-EBI ArrayExpress [70], or NCBI Gene Expression Omnibus (GEO) [71] websites. All WGCNA network files, module associations, preservation statistics and consensus data files generated in this publication are available upon request (andreas. neueder@kcl.ac.uk or andreas.neueder@web.de).

\section{Additional files}

Additional file 1: Illustrates the correlation between gene significance and eigengene based connectivity (KME).

Additional file 2: Figure illustrating the remaining cerebellum network modules.

Additional file 3: Figure illustrating the remaining frontal cortex BA4 network modules.

Additional file 4: Figure illustrating the remaining caudate nucleus network modules.

Additional file 5: Figure illustrating the remaining module of the consensus network analysis of HD and PD.

Additional file 6: Figure illustrating the consensus network analysis of $\mathrm{HD}$ and GG.

Additional file 7: Figure illustrating the consensus network analysis of $\mathrm{HD}$ and RCC.

Additional file 8: Figure illustrating the consensus network analysis of HD and DM1.

Additional file 9: Figure illustrating the consensus network analysis of HD and DM2.

Additional file 10: Figure illustrating the WGCNA analysis of the HD frontal cortex dataset with BA4 and BA9 regions combined.
Additional file 11: Table describing the gene ontology enrichment and upstream regulator analysis of the frontal cortex network with BA4 and BA9 regions combined.

\section{Abbreviations}

AD: Alzheimer's disease; ALS: Amyotrophic lateral sclerosis; BA4/9: Brodmann area 4/9; CB: Cerebellum; CN: Caudate nucleus; DCM: Dilated cardiomyopathy; DM1: Myotonic dystrophy type 1; DM2: Myotonic dystrophy type 2;

DMD: Duchenne Muscular Dystrophy; FC: Frontal cortex; GG: Ganglioglioma; GO: Gene ontology; HD: Huntington's disease; HTT: Huntingtin; MS: Multiple sclerosis; PD: Parkinson's disease; SCHIZ: Schizophrenia; WGCNA: Weighted gene correlation network analysis; RCC: Renal cell carcinoma.

\section{Competing interests}

The authors declare that they have no competing interests.

\section{Authors' contributions}

AN carried out the study. AN and GPB designed the study. AN and GPB wrote the manuscript. Both authors read and approved the final manuscript.

\section{Acknowledgements}

The authors would like to thank all tissue donors, without whom this research would have not been possible. We would also like to thank Dr. Alan Todd for help with the Biomedical Research Centre computer cluster and Theresa Gipson and David Housman (Koch Institute for Integrative Cancer Research at the Massachusetts Institute of Technology) for critically reading the manuscript.

\section{Funding}

This work was funded by the Medical Research Centre (MR/L003627/1) and supported by the National Institutes of Health Research Biomedical Research Centre at Guy's and St Thomas' NHS Foundation Trust in partnership with King's College London.

Received: 3 July 2014 Accepted: 6 October 2014

Published online: 30 October 2014

\section{References}

1. Riley BE, Orr HT: Polyglutamine neurodegenerative diseases and regulation of transcription: assembling the puzzle. Genes Dev 2006, 20:2183-2192.

2. Renner M, Melki R: Protein aggregation and prionopathies. Pathol Biol (Paris) 2014, 62:162-168.

3. Irwin DJ, Lee VM, Trojanowski JQ: Parkinson's disease dementia: convergence of alpha-synuclein, tau and amyloid-beta pathologies. Nat Rev Neurosci 2013, 14:626-636.

4. Rotunno MS, Bosco DA: An emerging role for misfolded wild-type SOD1 in sporadic ALS pathogenesis. Front Cell Neurosci 2013, 7:253.

5. Guo W, Chen Y, Zhou X, Kar A, Ray P, Chen X, Rao EJ, Yang M, Ye H, Zhu L, Liu J, Xu M, Yang Y, Wang C, Zhang D, Bigio EH, Mesulam M, Shen Y, Xu Q Fushimi K, Wu JY: An ALS-associated mutation affecting TDP-43 enhances protein aggregation, fibril formation and neurotoxicity. Nat Struct Mol Biol 2011, 18:822-830.

6. Nomura T, Watanabe S, Kaneko K, Yamanaka K, Nukina N, Furukawa Y: Intranuclear aggregation of mutant FUS/TLS as a molecular pathomechanism of amyotrophic lateral sclerosis. J Biol Chem 2014, 289:1192-1202.

7. Allende DS, Prayson RA: The expanding family of glioneuronal tumors. Adv Anat Pathol 2009, 16:33-39.

8. Ellwardt E, Zipp F: Molecular mechanisms linking neuroinflammation and neurodegeneration in MS. Exp Neurol 2014.

9. Gupta S, Kulhara P: What is schizophrenia: A neurodevelopmental or neurodegenerative disorder or a combination of both? A critical analysis. Indian J Psychiatry 2010, 52:21-27.

10. DeJesus-Hernandez M, Mackenzie IR, Boeve BF, Boxer AL, Baker M, Rutherford NJ, Nicholson AM, Finch NA, Flynn H, Adamson J, Kouri N, Wojtas A, Sengdy P, Hsiung GY, Karydas A, Seeley WW, Josephs KA, Coppola G, Geschwind DH, Wszolek ZK, Feldman H, Knopman DS, Petersen RC, Miller BL, Dickson DW, Boylan KB, Graff-Radford NR, Rademakers R: Expanded GGGGCC hexanucleotide repeat in noncoding region of C9ORF72 causes chromosome 9p-linked FTD and ALS. Neuron 2011, 72:245-256. 
11. Renton AE, Majounie E, Waite A, Simon-Sanchez J, Rollinson S, Gibbs JR, Schymick JC, Laaksovirta H, van Swieten JC, Myllykangas L, Kalimo H, Paetau A, Abramzon Y, Remes AM, Kaganovich A, Scholz SW, Duckworth J, Ding J, Harmer DW, Hernandez DG, Johnson JO, Mok K, Ryten M, Trabzuni D, Guerreiro RJ, Orrell RW, Neal J, Murray A, Pearson J, Jansen IE, et al: A hexanucleotide repeat expansion in C9ORF72 is the cause of chromosome 9p21-linked ALS-FTD. Neuron 2011, 72:257-268.

12. Ling SC, Polymenidou M, Cleveland DW: Converging mechanisms in ALS and FTD: disrupted RNA and protein homeostasis. Neuron 2013, 79:416-438.

13. Fardaei M, Rogers MT, Thorpe HM, Larkin K, Hamshere MG, Harper PS, Brook JD: Three proteins, MBNL, MBLL and MBXL, co-localize in vivo with nuclear foci of expanded-repeat transcripts in DM1 and DM2 cells. Hum Mol Genet 2002, 11:805-814.

14. Brook JD, Mccurrach ME, Harley HG, Buckler AJ, Church D, Aburatani H, Hunter K, Stanton VP, Thirion JP, Hudson T, Sohn R, Zemelman B, Snell RG, Rundle SA, Crow S, Davies J, Shelbourne P, Buxton J, Jones C, Juvonen V, Johnson K, Harper PS, Shaw DJ, Housman DE: Molecular basis of myotonic dystrophy: expansion of a trinucleotide (CTG) repeat at the $3^{\prime}$ end of a transcript encoding a protein kinase family member. Cell 1992, 68:799-808.

15. Mahadevan M, Tsilfidis C, Sabourin L, Shutler G, Amemiya C, Jansen G, Neville C, Narang M, Barcelo J, O'Hoy K, Ohoy K, Leblond S, Earlemacdonald J, Dejong PJ, Wieringa B, Korneluk RG: Myotonic dystrophy mutation: an unstable CTG repeat in the 3' untranslated region of the gene. Science 1992, 255:1253-1255.

16. Fu YH, Pizzuti A, Fenwick RG, King J, Rajnarayan S, Dunne PW, Dubel J, Nasser GA, Ashizawa T, Dejong P, Wieringa B, Korneluk R, Perryman MB, Epstein HF, Caskey CT: An unstable triplet repeat in a gene related to myotonic muscular dystrophy. Science 1992, 255:1256-1258.

17. Liquori CL, Ricker K, Moseley ML, Jacobsen JF, Kress W, Naylor SL, Day JW, Ranum LP: Myotonic dystrophy type 2 caused by a CCTG expansion in intron 1 of ZNF9. Science 2001, 293:864-867.

18. Kanadia RN, Johnstone KA, Mankodi A, Lungu C, Thornton CA, Esson D, Timmers AM, Hauswirth WW, Swanson MS: A muscleblind knockout model for myotonic dystrophy. Science 2003, 302:1978-1980.

19. Sathasivam K, Neueder A, Gipson TA, Landles C, Benjamin AC, Bondulich MK, Smith DL, Faull RLM, Roos RAC, Howland D, Detloff PJ, Housman DE, Bates GP: Aberrant splicing of $\mathrm{HTT}$ generates the pathogenic exon 1 protein in Huntington disease. Proc Natl Acad Sci U S A 2013, 110:2366-2370.

20. Cooper-Knock J, Kirby J, Ferraiuolo L, Heath PR, Rattray M, Shaw PJ: Gene expression profiling in human neurodegenerative disease. Nat Rev Neurol 2012, 8:518-530.

21. Chandra A, Johri A, Beal MF: Prospects for neuroprotective therapies in prodromal Huntington's disease. Mov Disord 2014, 29(Suppl 3):285-293.

22. Ross CA, Shoulson I: Huntington disease: pathogenesis, biomarkers, and approaches to experimental therapeutics. Parkinsonism Relat Disord 2009, 15(Suppl 3):S135-138.

23. Bjorkqvist $M$, Wild EJ, Thiele J, Silvestroni A, Andre R, Lahiri N, Raibon E, Lee RV, Benn CL, Soulet D, Magnusson A, Woodman B, Landles C, Pouladi MA, Hayden MR, Khalili-Shirazi A, Lowdell MW, Brundin P, Bates GP, Leavitt BR, Moller T, Tabrizi SJ: A novel pathogenic pathway of immune activation detectable before clinical onset in Huntington's disease. J Exp Med 2008, 205:1869-1877.

24. Becanovic K, Pouladi MA, Lim RS, Kuhn A, Pavlidis P, Luthi-Carter R, Hayden MR, Leavitt BR: Transcriptional changes in Huntington disease identified using genome-wide expression profiling and cross-platform analysis. Hum Mol Genet 2010, 19:1438-1452.

25. Zabel C, Mao L, Woodman B, Rohe M, Wacker MA, Klare Y, Koppelstatter A, Nebrich G, Klein O, Grams S, Strand A, Luthi-Carter R, Hartl D, Klose J, Bates GP: A large number of protein expression changes occur early in life and precede phenotype onset in a mouse model for huntington disease. Mol Cell Proteomics 2009, 8:720-734.

26. Benn CL, Sun T, Sadri-Vakili G, McFarland KN, DiRocco DP, Yohrling GJ, Clark TW, Bouzou $\mathrm{B}, \mathrm{Cha} \mathrm{JH}$ : Huntingtin modulates transcription, occupies gene promoters in vivo, and binds directly to DNA in a polyglutaminedependent manner. J Neurosci 2008, 28:10720-10733.

27. Hodges A, Strand AD, Aragaki AK, Kuhn A, Sengstag T, Hughes G, Elliston LA, Hartog C, Goldstein DR, Thu D, Hollingsworth ZR, Collin F, Synek B, Holmans PA, Young AB, Wexler NS, Delorenzi M, Kooperberg C, Augood SJ, Faull RLM, Olson JM, Jones L, Luthi-Carter R: Regional and cellular gene expression changes in human Huntington's disease brain. Hum Mol Genet 2006, 15:965-977.
28. Kuhn A, Goldstein DR, Hodges A, Strand AD, Sengstag T, Kooperberg C, Becanovic K, Pouladi MA, Sathasivam K, Cha JH, Cha JHJ, Hannan AJ, Hayden MR, Leavitt BR, Dunnett SB, Ferrante RJ, Albin R, Shelbourne P, Delorenzi M, Augood SJ, Faull RLM, Olson JM, Bates GP, Jones L, LuthiCarter R: Mutant huntingtin's effects on striatal gene expression in mice recapitulate changes observed in human Huntington's disease brain and do not differ with mutant huntingtin length or wild-type huntingtin dosage. Hum Mol Genet 2007, 16:1845-1861.

29. Langfelder $P$, Horvath S: WGCNA: an R package for weighted correlation network analysis. BMC Bioinformatics 2008, 9:559.

30. Oldham MC, Konopka G, Iwamoto K, Langfelder P, Kato T, Horvath S, Geschwind DH: Functional organization of the transcriptome in human brain. Nat Neurosci 2008, 11:1271-1282.

31. Oldham MC, Horvath S, Geschwind DH: Conservation and evolution of gene coexpression networks in human and chimpanzee brains. Proc Nat Acad Sci U S A 2006, 103:17973-17978.

32. Saris CGJ, Horvath $S$, van Vught PWJ, van Es MA, Blauw HM, Fuller TF, Langfelder P, DeYoung J, Wokke JHJ, Veldink JH, van den Berg LH, Ophoff RA: Weighted gene co-expression network analysis of the peripheral blood from Amyotrophic Lateral Sclerosis patients. BMC Genomics 2009, 10:405.

33. Miller JA, Oldham MC, Geschwind DH: A systems level analysis of transcriptional changes in Alzheimer's disease and normal aging. J Neurosci 2008, 28:1410-1420.

34. Miller JA, Horvath S, Geschwind DH: Divergence of human and mouse brain transcriptome highlights Alzheimer disease pathways. Proc Natl Acad Sci U S A 2010, 107:12698-12703.

35. Durrenberger PF, Fernando FS, Magliozzi R, Kashefi SN, Bonnert TP, Ferrer I, Seilhean D, Nait-Oumesmar B, Schmitt A, Gebicke-Haerter PJ, Falkai P, Grunblatt E, Palkovits M, Parchi P, Capellari S, Arzberger T, Kretzschmar H, Roncaroli F, Dexter DT, Reynolds R: Selection of novel reference genes for use in the human central nervous system: a BrainNet Europe Study. Acta Neuropathol 2012, 124:893-903.

36. Pouladi MA, Morton AJ, Hayden MR: Choosing an animal model for the study of Huntington's disease. Nat Rev Neurosci 2013, 14:708-721.

37. Bates GP, Landles C: Preclinical Experimental Therapeutics. In Huntington's Disease. Volume Fourthth edition. Edited by Bates GP, Tabrizi SJ, Jones L. OUP USA: Oxford Monographs on Medical Genetics; 2014:410-461.

38. Oldham MC, Langfelder P, Horvath S: Network methods for describing sample relationships in genomic datasets: application to Huntington's disease. BMC Syst Biol 2012, 6:63.

39. Vonsattel JP, Myers RH, Stevens TJ, Ferrante RJ, Bird ED, Richardson EP Jr: Neuropathological classification of Huntington's disease. J Neuropatho Exp Neurol 1985, 44:559-577.

40. Bayram-Weston Z, Torres EM, Jones L, Dunnett SB, Brooks SP: Light and electron microscopic characterization of the evolution of cellular pathology in the Hdh(CAG)150 Huntington's disease knock-in mouse. Brain Res Bull 2012, 88:189-198.

41. Dodds L, Chen J, Berggren K, Fox J: Characterization of Striatal Neuronal Loss and Atrophy in the R6/2 Mouse Model of Huntington's Disease. PLOS Curr 2014, 6.

42. Rattray I, Smith E, Gale R, Matsumoto K, Bates GP, Modo M: Correlations of behavioral deficits with brain pathology assessed through longitudinal MRI and histopathology in the R6/2 mouse model of HD. PLOS One 2013, 8:e60012.

43. Zuccato C, Valenza M, Cattaneo E: Molecular mechanisms and potential therapeutical targets in Huntington's disease. Physiol Rev 2010, 90:905-981.

44. Chen CM: Mitochondrial dysfunction, metabolic deficits, and increased oxidative stress in Huntington's disease. Chang Gung Med J 2011, 34:135-152.

45. Fossale E, Seong IS, Coser KR, Shioda T, Kohane IS, Wheeler VC, Gusella JF, MacDonald ME, Lee JM: Differential effects of the Huntington's disease CAG mutation in striatum and cerebellum are quantitative not qualitative. Hum Mol Genet 2011, 20:4258-4267.

46. Khatri $P$, Draghici S: Ontological analysis of gene expression data: current tools, limitations, and open problems. Bioinformatics 2005, 21:3587-3595.

47. Langfelder P, Mischel PS, Horvath S: When is hub gene selection better than standard meta-analysis? PLoS One 2013, 8:e61505.

48. Soulet $D$, Cicchetti $F$ : The role of immunity in Huntington's disease. Mol Psychiatry 2011, 16:889-902.

49. Zhang B, Gaiteri C, Bodea LG, Wang Z, McElwee J, Podtelezhnikov AA, Zhang CS, Xie T, Tran L, Dobrin R, Fluder E, Clurman B, Melquist S, 
Narayanan M, Suver C, Shah H, Mahajan M, Gillis T, Mysore J, MacDonald ME, Lamb JR, Bennett DA, Molony C, Stone DJ, Gudnason V, Myers AJ, Schadt EE, Neumann H, Zhu J, Emilsson V: Integrated systems approach identifies genetic nodes and networks in late-onset Alzheimer's disease. Cell 2013, 153:707-720

50. Venkova-Hristova K, Christov A, Kamaluddin Z, Kobalka P, Hensley K: Progress in therapy development for amyotrophic lateral sclerosis. Neurol Res Int 2012, 2012:187234

51. Kantarci OH, Pirko I, Rodriguez M: Novel immunomodulatory approaches for the management of multiple sclerosis. Clin Pharmacol Ther 2014 95:32-44.

52. Deleidi M, Gasser $\mathrm{T}$ : The role of inflammation in sporadic and familial Parkinson's disease. Cell Mol Life Sci 2013, 70:4259-4273.

53. Crotti A, Benner C, Kerman BE, Gosselin D, Lagier-Tourenne C, Zuccato C, Cattaneo E, Gage FH, Cleveland DW, Glass CK: Mutant Huntingtin promotes autonomous microglia activation via myeloid lineage-determining factors. Nat Neurosci 2014, 17:513-521.

54. Tong X, Ao Y, Faas GC, Nwaobi SE, Xu J, Haustein MD, Anderson MA, Mody I, Olsen ML, Sofroniew MV, Khakh BS: Astrocyte Kir4.1 ion channel deficits contribute to neuronal dysfunction in Huntington's disease model mice. Nat Neurosci 2014, 17:694-703.

55. Singhrao SK, Neal JW, Morgan BP, Gasque P: Increased complement biosynthesis by microglia and complement activation on neurons in Huntington's disease. Exp Neurol 1999, 159:362-376.

56. Rus H, Cudrici C, David S, Niculescu F: The complement system in central nervous system diseases. Autoimmunity 2006, 39:395-402.

57. Labbadia J, Morimoto Rl: Huntington's disease: underlying molecular mechanisms and emerging concepts. Trends Biochem Sci 2013, 38:378-385.

58. Carnemolla A, Labbadia JP, Lazell H, Neueder A, Moussaoui S, Bates GP: Contesting the dogma of an age-related heat shock response impairment: implications for cardiac-specific age-related disorders. Hum Mol Genet 2014 23:3641-3656.

59. Fernandez-Nogales M, Cabrera JR, Santos-Galindo M, Hoozemans JJ, Ferrer I, Rozemuller AJ, Hernandez F, Avila J, Lucas JJ: Huntington's disease is a four-repeat tauopathy with tau nuclear rods. Nat Med 2014, 20:881-885.

60. Scarffe LA, Stevens DA, Dawson VL, Dawson TM: Parkin and PINK1: much more than mitophagy. Trends Neurosci 2014, 37:315-324

61. Jin K, LaFevre-Bernt M, Sun Y, Chen S, Gafni J, Crippen D, Logvinova A, Ross CA, Greenberg DA, Ellerby LM: FGF-2 promotes neurogenesis and neuroprotection and prolongs survival in a transgenic mouse model of Huntington's disease. Proc Natl Acad Sci U S A 2005, 102:18189-18194.

62. Hands SL, Mason R, Sajjad MU, Giorgini F, Wyttenbach A: Metallothioneins and copper metabolism are candidate therapeutic targets in Huntington's disease. Biochem Soc Trans 2010, 38:552-558.

63. Labbadia J, Cunliffe H, Weiss A, Katsyuba E, Sathasivam K, Seredenina T, Woodman B, Moussaoui S, Frentzel S, Luthi-Carter R, Paganetti P, Bates GP: Altered chromatin architecture underlies progressive impairment of the heat shock response in mouse models of Huntington disease. J Clin Invest 2011, 121:3306-3319.

64. Hayashida N, Fujimoto M, Tan K, Prakasam R, Shinkawa T, Li L, Ichikawa H, Takii R, Nakai A: Heat shock factor 1 ameliorates proteotoxicity in cooperation with the transcription factor NFAT. EMBO J 2010, 29:3459-3469.

65. Vidal RL, Figueroa A, Court FA, Thielen P, Molina C, Wirth C, Caballero B, Kiffin R, Segura-Aguilar J, Cuervo AM, Glimcher LH, Hetz C: Targeting the UPR transcription factor XBP1 protects against Huntington's disease through the regulation of FoxO1 and autophagy. Hum Mol Genet 2012, 21:2245-2262

66. Anglada-Huguet M, Giralt A, Perez-Navarro E, Alberch J, Xifro X: Activation of Elk-1 participates as a neuroprotective compensatory mechanism in models of Huntington's disease. J Neurochem 2012, 121:639-648.

67. Perrin V, Dufour N, Raoul C, Hassig R, Brouillet E, Aebischer P, Luthi-Carter R, Deglon N: Implication of the JNK pathway in a rat model of Huntington's disease. Exp Neurol 2009, 215:191-200.

68. Rigamonti D, Mutti C, Zuccato C, Cattaneo E, Contini A: Turning REST/NRSF dysfunction in Huntington's disease into a pharmaceutical target. Curr Pharm Des 2009, 15:3958-3967.

69. Steffan JS, Kazantsev A, Spasic-Boskovic O, Greenwald M, Zhu YZ, Gohler H, Wanker EE, Bates GP, Housman DE, Thompson LM: The Huntington's disease protein interacts with $\mathrm{p} 53$ and CREB-binding protein and represses transcription. Proc Natl Acad Sci U S A 2000, 97:6763-6768.
70. Rustici G, Kolesnikov N, Brandizi M, Burdett T, Dylag M, Emam I, Farne A, Hastings E, Ison J, Keays M, Kurbatova N, Malone J, Mani R, Mupo A, Pedro Pereira R, Pilicheva E, Rung J, Sharma A, Tang YA, Ternent T, Tikhonov A, Welter D, Williams E, Brazma A, Parkinson H, Sarkans U: ArrayExpress update-trends in database growth and links to data analysis tools. Nucleic Acids Res 2013, 41:D987-990.

71. Barrett T, Wilhite SE, Ledoux P, Evangelista C, Kim IF, Tomashevsky M, Marshall KA, Phillippy KH, Sherman PM, Holko M, Yefanov A, Lee H, Zhang N, Robertson CL, Serova N, Davis S, Soboleva A: NCBI GEO: archive for functional genomics data sets-update. Nucleic Acids Res 2013, 41:D991-995.

72. Lim WK, Wang K, Lefebvre C, Califano A: Comparative analysis of microarray normalization procedures: effects on reverse engineering gene networks. Bioinformatics 2007, 23:i282-288

73. Miller JA, Cai C, Langfelder P, Geschwind DH, Kurian SM, Salomon DR, Horvath S: Strategies for aggregating gene expression data: the collapseRows R function. BMC Bioinformatics 2011, 12:322.

74. Langfelder $P$, Zhang B, Horvath S: Defining clusters from a hierarchical cluster tree: the Dynamic Tree Cut package for R. Bioinformatics 2008, 24:719-720.

75. Chen BE, Sakoda LC, Hsing AW, Rosenberg PS: Resampling-based multiple hypothesis testing procedures for genetic case-control association studies. Genet Epidemiol 2006, 30:495-507.

76. Langfelder $\mathrm{P}$, Luo R, Oldham MC, Horvath S: Is my network module preserved and reproducible? PLoS Comput Biol 2011, 7:e1001057.

77. Shannon P, Markiel A, Ozier O, Baliga NS, Wang JT, Ramage D, Amin N, Schwikowski B, Ideker T: Cytoscape: a software environment for integrated models of biomolecular interaction networks. Genome Res 2003, 13:2498-2504.

78. Zambon AC, Gaj S, Ho I, Hanspers K, Vranizan K, Evelo CT, Conklin BR, Pico AR, Salomonis N: GO-Elite: a flexible solution for pathway and ontology over-representation. Bioinformatics 2012, 28:2209-2210.

79. Zhang B, Kirov S, Snoddy J: WebGestalt: an integrated system for exploring gene sets in various biological contexts. Nucleic Acids Res 2005 33:W741-748.

80. da Huang W, Sherman BT, Lempicki RA: Systematic and integrative analysis of large gene lists using DAVID bioinformatics resources. Nat Protoc 2009, 4:44-57.

81. Vihola A, Bachinski LL, Sirito M, Olufemi SE, Hajibashi S, Baggerly KA, Raheem O, Haapasalo H, Suominen T, Holmlund-Hampf J, Paetau A, Cardani R, Meola G, Kalimo H, Edstrom L, Krahe R, Udd B: Differences in aberrant expression and splicing of sarcomeric proteins in the myotonic dystrophies DM1 and DM2. Acta Neuropathol 2010, 119:465-479.

82. Pescatori M, Broccolini A, Minetti C, Bertini E, Bruno C, D'Amico A, Bernardini C, Mirabella M, Silvestri G, Giglio V, Modoni A, Pedemonte M, Tasca G, Galluzzi G, Mercuri E, Tonali PA, Ricci E: Gene expression profiling in the early phases of DMD: a constant molecular signature characterizes DMD muscle from early postnatal life throughout disease progression. FASEB J 2007, 21:1210-1226

83. Barth AS, Kuner R, Buness A, Ruschhaupt M, Merk S, Zwermann L, Kaab S, Kreuzer E, Steinbeck G, Mansmann U, Poustka A, Nabauer M, Sultmann H: Identification of a common gene expression signature in dilated cardiomyopathy across independent microarray studies. J Am Coll Cardiol 2006, 48:1610-1617.

84. Lenburg ME, Liou LS, Gerry NP, Frampton GM, Cohen HT, Christman MF: Previously unidentified changes in renal cell carcinoma gene expression identified by parametric analysis of microarray data. BMC Cancer 2003 3:31.

85. Fassunke J, Majores M, Tresch A, Niehusmann P, Grote A, Schoch S, Becker AJ: Array analysis of epilepsy-associated gangliogliomas reveals expression patterns related to aberrant development of neuronal precursors. Brain 2008, 131:3034-3050.

\section{doi:10.1186/s12920-014-0060-2}

Cite this article as: Neueder and Bates: A common gene expression signature in Huntington's disease patient brain regions. BMC Medical Genomics 2014 7:60. 